\title{
The Effects Of Stress Mitigation On Nondestructive Examination
}

Dennis C. Kunerth Timothy R. McJunkin

Eric D. Larsen

Arthur D. Watkins

August 2004

Idaho National Engineering and Environmental Laboratory Bechtel BWXT Idaho, LLC 

INEEL/EXT-04-02199

\title{
The Effects of Stress Mitigation on Nondestructive Examination
}

\author{
Dennis C. Kunerth, Timothy R. McJunkin,
}

Eric D. Larsen, Arthur D. Watkins

\begin{abstract}
August 2004
Idaho National Engineering and Environmental Laboratory
\end{abstract}

Idaho Falls, Idaho 83415

Prepared for the

U.S. Department of Energy

Assistant Secretary for Environmental Management

Under DOE Idaho Operations Office

Contract DE-AC07-99ID13727 


\title{
The Effects of Stress Mitigation on Nondestructive Examination
}

\author{
INEELEXT-04-02199
}

August 2004

Approved by
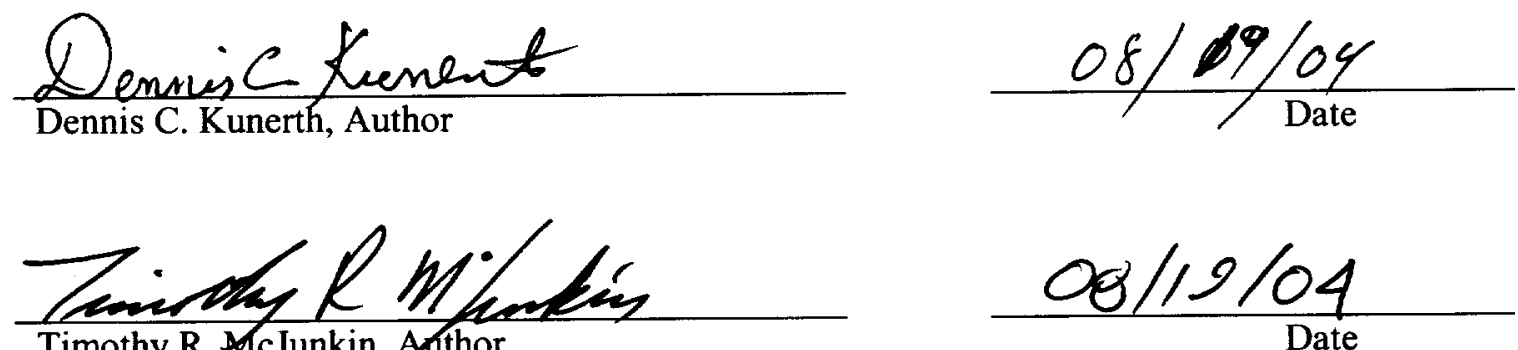

Timothy R. ArJunkin, Anthor
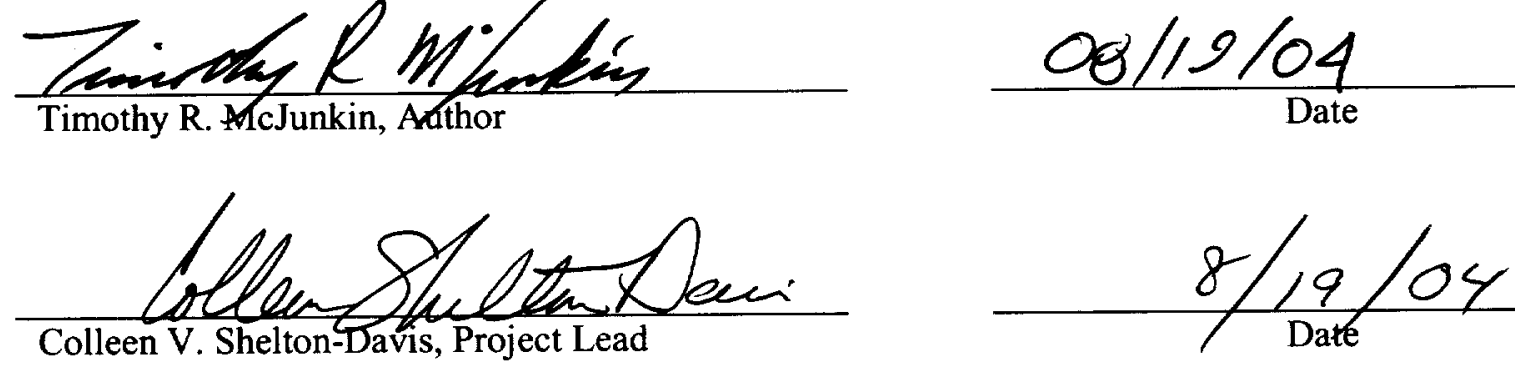


\begin{abstract}
Ultrasonic volumetric and eddy current and visual profile surface inspections of the completed weld securing the outer lid of the Yucca Mountain waste package are required after stress mitigation. However, the technique implemented may affect the ability of the different evaluation techniques to properly characterize the completed weld. An evaluation was performed to determine the extent the nondestructive evaluation techniques are affected by two candidate mitigation processes: controlled plasticity burnishing and laser peening. This report describes the work performed and summarizes the results.
\end{abstract}




\section{CONTENTS}

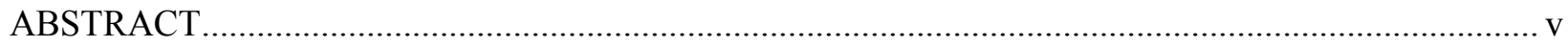

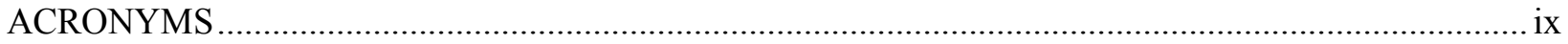

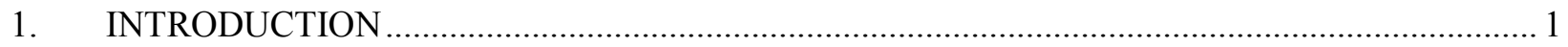

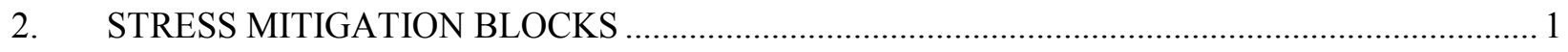

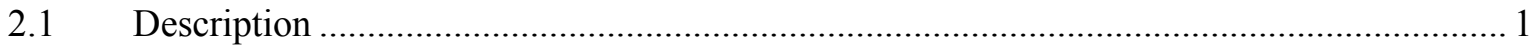

2.2 Addition of Simulated Flaws and Other Block Preparation .......................................... 3

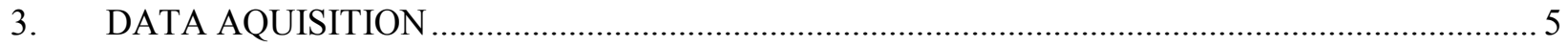

3.1 Ultrasonic Equipment and Data Acquisition Plan ....................................................... 5

3.2 Eddy Current Equipment and Data Acquisition Plan.................................................. 6

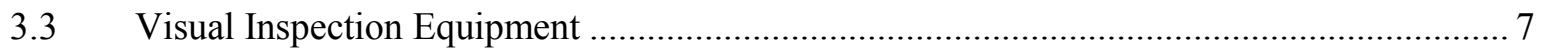

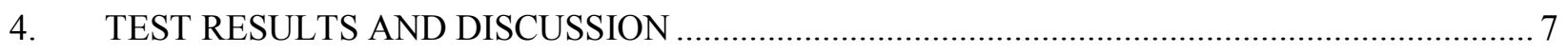

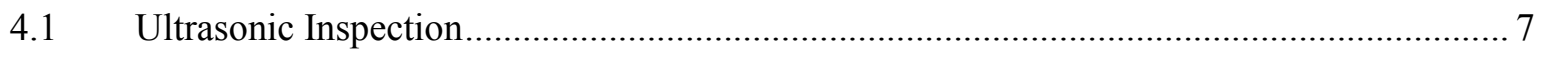

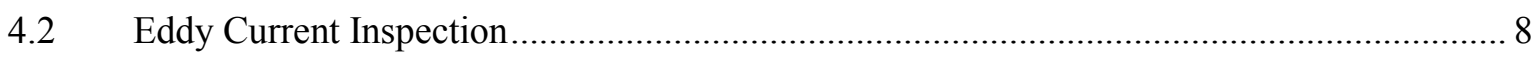

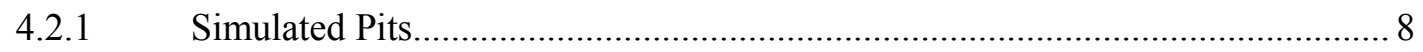

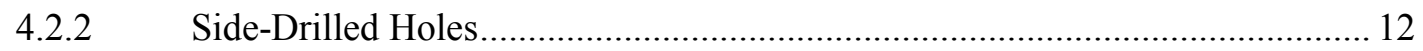

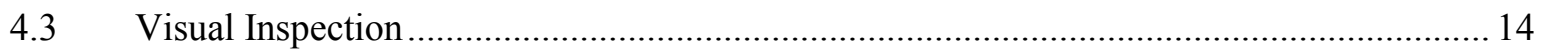

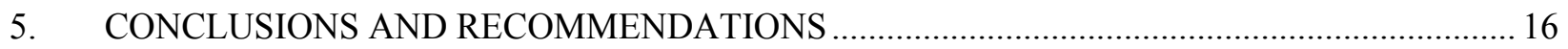

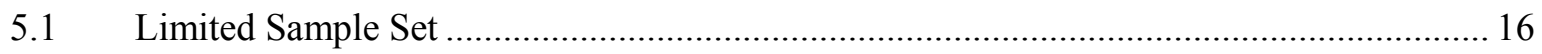

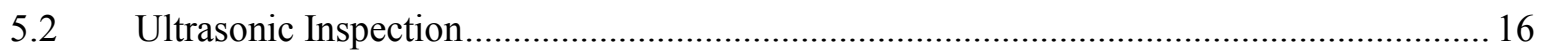

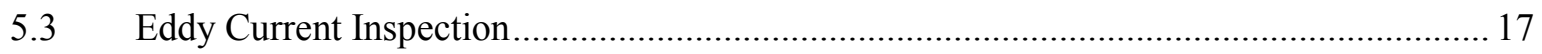

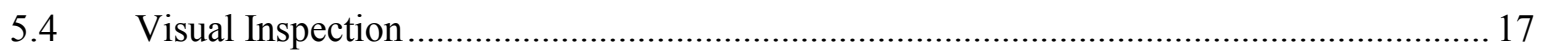

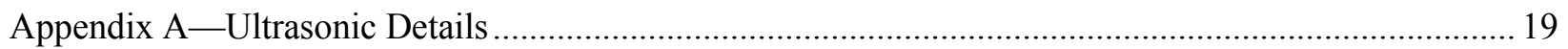

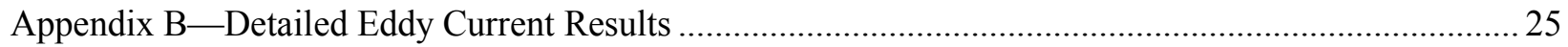

Appendix C_-Example of the Problem Caused by a Reflective Surface for the Visual Sensor ............... 39 


\section{FIGURES}

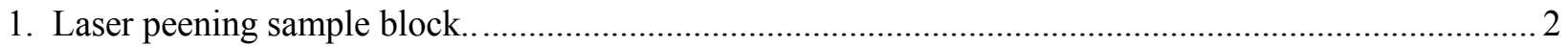

2. Controlled plasticity burnishing sample block........................................................................ 2

3. Drawing of the target locations in the controlled plasticity burnishing sample block......................... 3

4. Drawing of target locations in the laser peening sample block. .................................................... 4

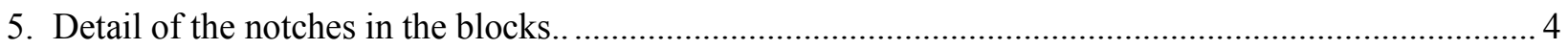

6. Eddy current raster scans of stress mitigation test blocks........................................................ 9

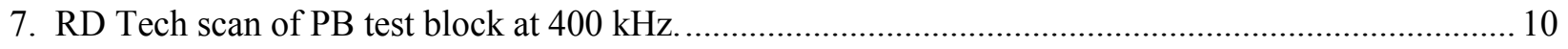

8. Surface plots of the raster scans collected at $240 \mathrm{kHz}$ for the two mitigation test blocks.................... 11

9. Raster scans over the side-drilled holes in the low plasticity burnished test block. .......................... 13

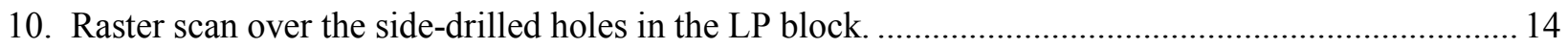

11. Profile measured across a typical profile of each section of the blocks and the worst

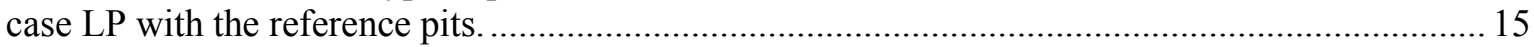

\section{TABLES}

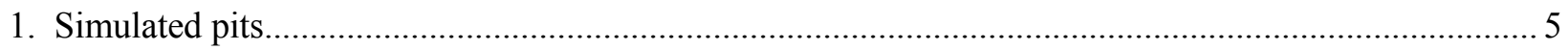

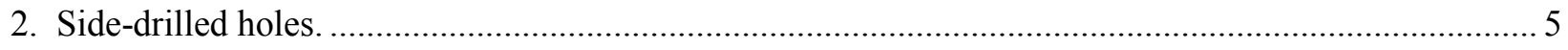

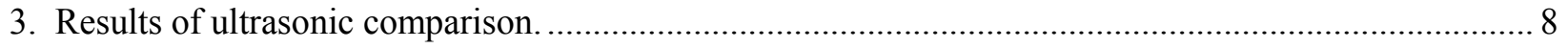

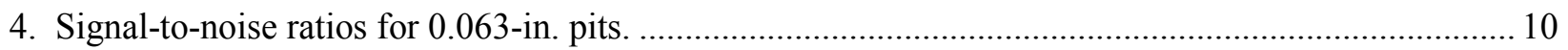




\section{ACRONYMS}

BSC Bechtel SAIC, LLC

INEEL Idaho National Engineering and Environmental Laboratory

LLNL Lawerence Livermore National Laboratory

LP laser peening

PB controlled plasticity burnishing 


\section{The Effects of Stress Mitigation on Nondestructive Examination}

\section{INTRODUCTION}

Ultrasonic, eddy current, and visual inspections of the completed weld securing the outer lid of the Yucca Mountain waste package are required after stress mitigation. Since the objective of the stress mitigation process is to modify the residual surface stresses via manipulation of the physical and material properties of the surface, the nature of the process implemented may affect the functionality of the inspection techniques. Modification of the surface locally alters the mechanical properties that define acoustic wave generation, propagation, and reflection characteristics. Also modified is the electrical conductivity that defines eddy current generation and penetration. Any surface contours created by the stress mitigation may be detected by the visual profiling sensor and thus have an effect on the inspection. The objective of this investigation is to characterize to what extent the three nondestructive evaluation techniques are affected by the candidate mitigation processes, controlled plasticity burnishing and laser peening. This will be accomplished via laboratory measurements comparing ultrasonic, eddy current, and visual profiling sensor responses to machined structures in stress mitigated and unmitigated regions in alloy 22 blocks. Although environmental conditions in the Yucca Mountain waste package closure cell may influence the available signal-to-noise levels in any of these techniques, only relative differences between the two stress mitigation techniques are reported herein.

\section{STRESS MITIGATION BLOCKS}

\subsection{Description}

A test block for each stress mitigation technique was obtained for evaluation. One block was stress mitigated with a laser peening (LP) method. This block, provided by Lawerence Livermore National Laboratory (LLNL), had a portion of its surface (including the weld) treated by the LP mitigation method and a portion left in the as-received un-stress-mitigated condition. Figure 1 shows a photograph of the top surface of the LP block. The block is nominally 1 in. thick with no marked difference in the thickness between the stress-mitigated and un-stress-mitigated sections. The stress-mitigated section extended about 2 in. from the weld reinforcement on the block. A significant area was left without stress mitigation. The block had large bracing structure attached to the bottom of the block presumably to support the block during welding. A metal channel was welded to the bottom side over the weld joint location. The purpose of this channel is unknown.

It was observed that the LP process was a raster process, with the primary direction of the raster parallel to the weld bead (that is, the laser spot was moved in a line down the weld, then shifted horizontally and the line repeated). This resulted in obvious shallow "grooves" parallel to the weld in this block. In the actual process, on a waste package the primary raster direction will be transverse to the weld to avoid making many circumferential passes over the package. During the actual processing, the primary inspection with ultrasonic test equipment will direct the ultrasonic signal in a direction transverse to the weld. The experiments performed for this report have an orientation with respect to the grooves that corresponds to the proper orientation of the LP raster to the weld bead in the actual waste package. The ultrasound probe in the experiments described in this report is directed at the targets in the LP block such that the horizontal component of the sound path was in the same direction as the raster, to be consistent with the relative direction on the actual waste package. This configuration of the block allowed the experiment to be performed over larger angles of incidence.

A second block was welded at the Idaho National Engineering and Environmental Laboratory (INEEL) and provided to Bechtel SAIC, LLC (BSC) for compressive stress mitigation by controlled low 
plasticity burnishing (PB). BSC provided INEEL the material for the block. One side of the block is 1.31 in. thick; the other side is 1.5 in. thick. PB stress mitigation was performed over the weld crown and about 2 in. to each side of the weld crown. Portions of the block outside the stress-mitigated area were left unchanged. Figure 2 shows a photograph of the top surface of the PB block. There is no apparent direction to a surface texture on the PB stress-mitigated area. The surface, as is apparent in Figure 2, is very smooth. An abrupt elevation change occurs at the edges of the stress-mitigated area, which is about 0.04 in. lower than the base material surface.

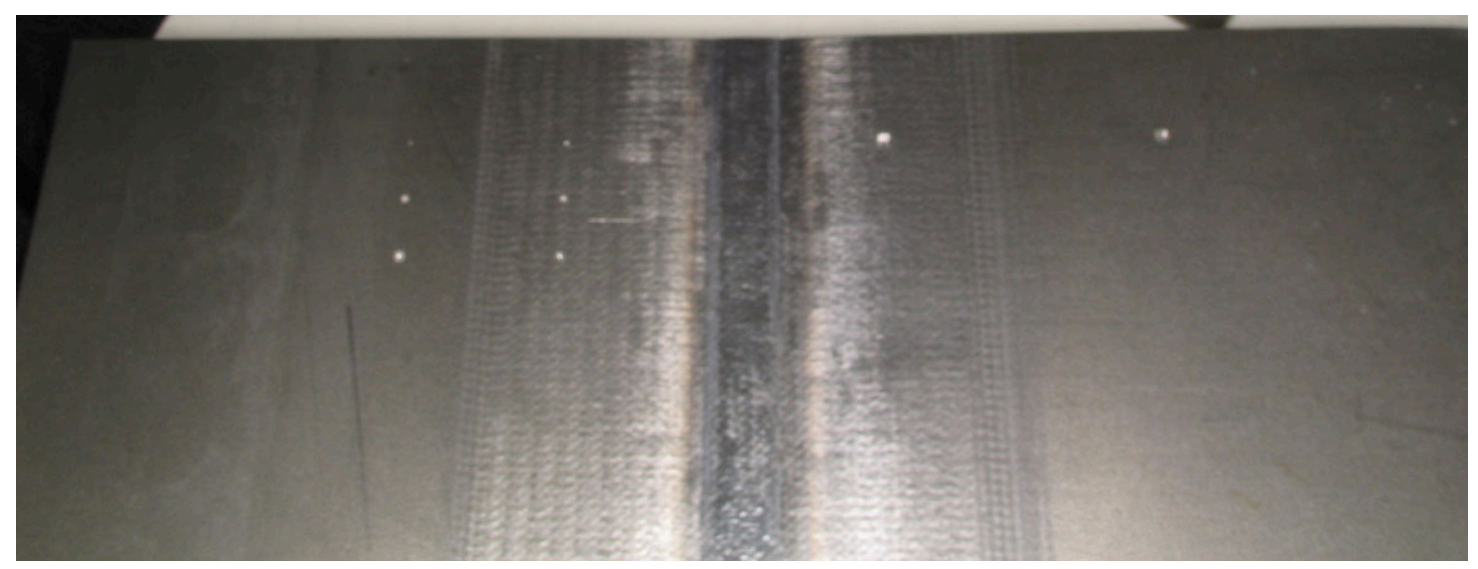

Figure 1. Laser peening sample block. The laser peened section is the 4.4-in.-wide textured area centered over the weld. The remaining areas are in the as-received condition. Simulated pit targets are visible on the left side. Notches used for the ultrasonic measurements are located on the bottom side of the block under the right side surface in this image. Topside notches of the same size are visible on the right side.

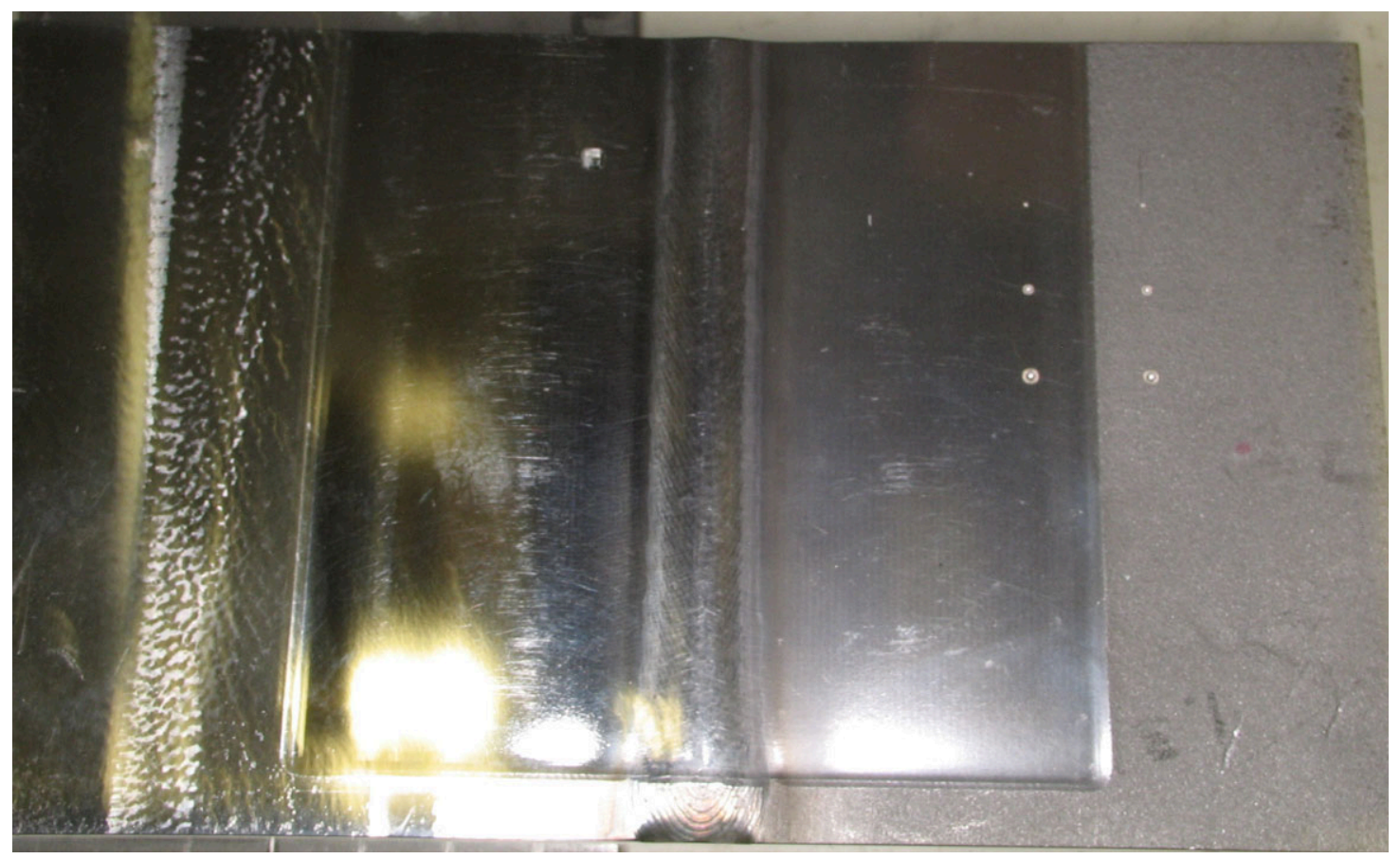

Figure 2. Controlled plasticity burnishing sample block. The stress-mitigated area is the smooth 4.25-in.wide area centered over the weld. The area on the left has been faced with a cutting tool, while the area on the right is in the as-received condition. Simulated pit targets are visible on the right side. Notches used for the ultrasonic measurements are located on the bottom side of the block under the left side surface in 
this image. Top side notches of the same size are visible on the right side of the image. An abrupt transition from the stress-mitigate area to the base material is visible in the photograph.

\subsection{Addition of Simulated Flaws and Other Block Preparation}

To accomplish a fair comparison between the two blocks, any differences between them were normalized. For the ultrasonic process evaluation, there were two significant differences between the blocks. First, there was an intrinsic difference in the thickness of the two blocks. The LP block was 1.04 in. thick; the PB block was 1.31 in. thick on the side chosen for ultrasonic targets. This side was chosen to minimize the difference in thickness, since the other side was even thicker. Second, the materials for the two blocks were from different heats. Therefore, to normalize the possible variation in attenuation of ultrasound from the two blocks due to differences in material chemical composition and thickness, identical targets for the ultrasonic experiment were placed both under the stress mitigated area and under the untreated base material surfaces on both blocks. The targets under the base material serve the purpose of a reference target for use in determining the system's response to a standard target. The response of the system verifies the functionality of the system for comparison to the stress-mitigated material target.

The targets chosen for the ultrasonic comparison were small notches located on the bottom side of the block. These notches were $0.063 \mathrm{in}$. deep and had a flat face that was $0.063 \mathrm{in}$. long. The radius of the cutting tool used to machine these notches was 0.031 inches. Thus, the effective vertical surface used in the ultrasonic reflection was $0.063 \mathrm{in}$. by $0.063 \mathrm{in}$. The locations of the notches were chosen to allow the probe to be completely over the stress-mitigated surface when scanning the target on that side and completely on the base-metal side when scanning for that target. Figures 3 and 4 show locations of notches relative to the stress mitigation area on each block. Figure 5 shows a detail view of the notches.

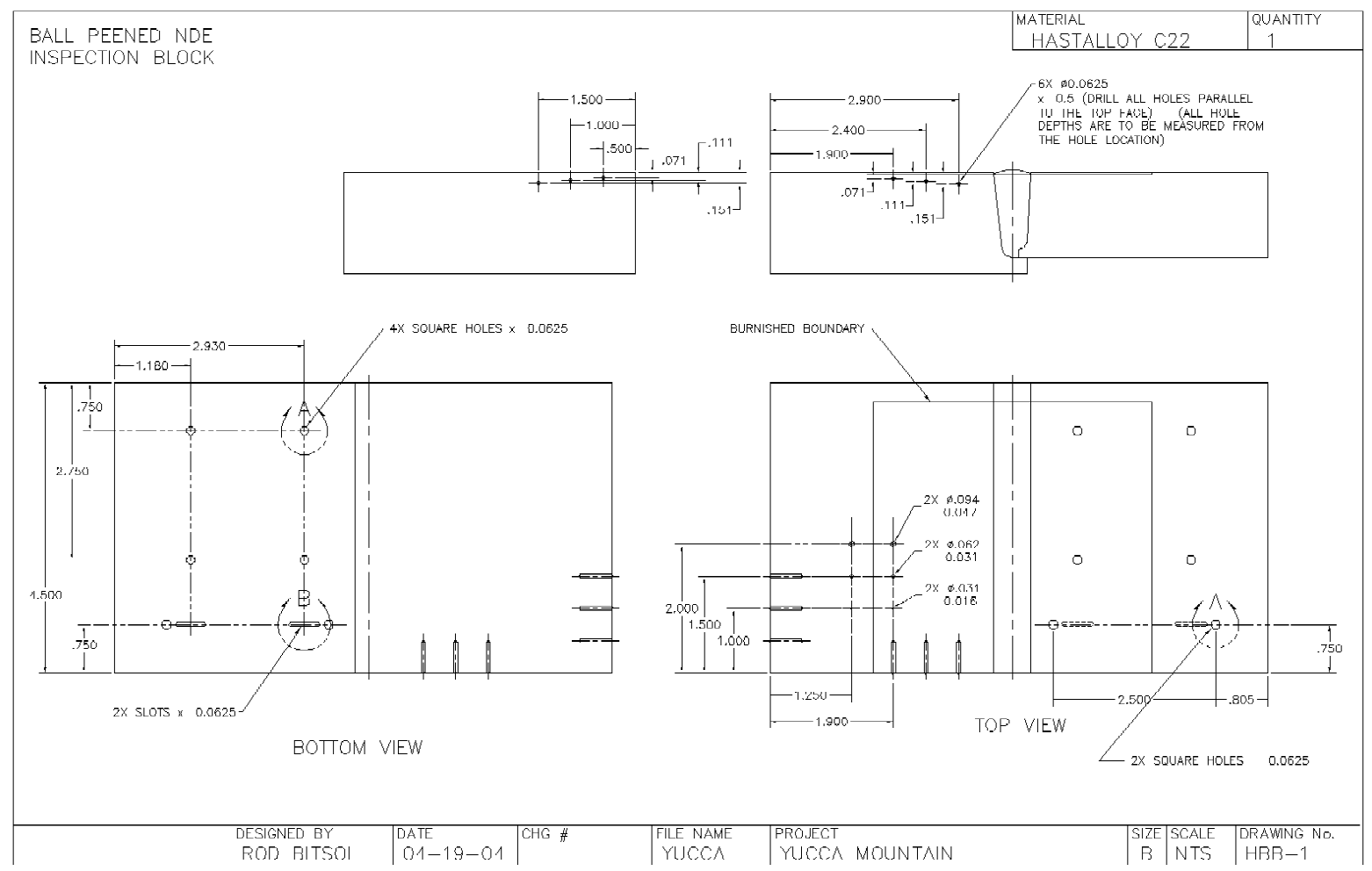

Figure 3. Drawing of the target locations in the controlled plasticity burnishing sample block. Targets include simulated pits, notches, and side drill holes, identical flaws that are in both the base material and stress-mitigated areas. 


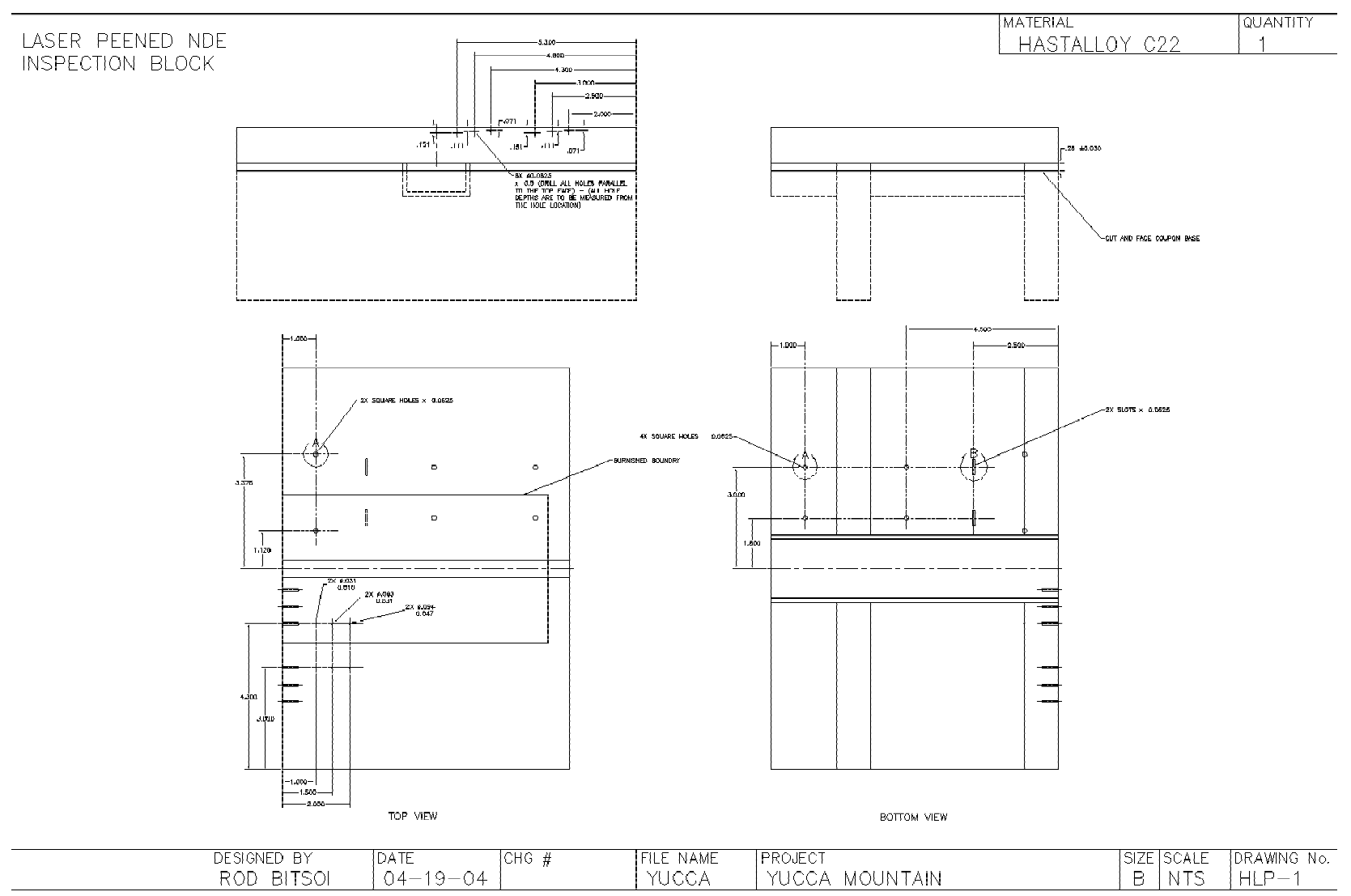

Figure 4. Drawing of target locations in the laser peening sample block. Targets include simulated pits, notches, and side drill holes, identical flaws that are in both the base material and stress mitigated areas.

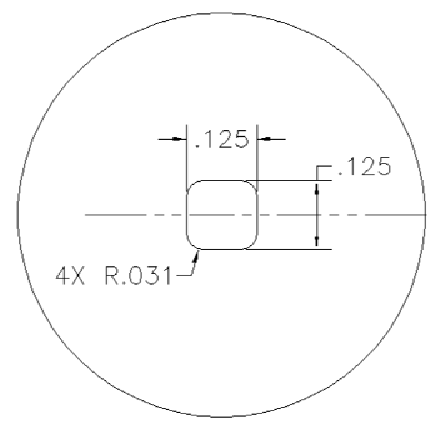

Figure 5. Detail of the notches in the blocks. The notches are 0.063 in. deep.

Two different types of simulated flaws were used to evaluate the eddy current responses. The first was a series of simulated pits machined into the surface of the two mitigation samples using ball endmills. The series consisted of three pits that bracketed the 0.063 -in.-minimum flaw size (see Table 1). Identical sets of pits were placed in unmitigated and mitigated sections in both test blocks. As with the ultrasonic inspection, this approach permits direct comparison of the eddy current responses for each surface condition in a single test block without the material differences that may result from heat-to-heat variations. The second was an identical set of 0.063-in.-diameter side-drilled holes varying in depth from the top surface (see Table 2). The objective of machining these holes was to evaluate the effects of mitigation on the ability to detect near-surface defects. Figures 3 and 4 show the locations of these 
features. The targets in the base material act as reference targets to establish the system's baseline response. Responses from identical targets located in the mitigated regions can then be compared to the baseline responses to determine relative changes in the recorded signals due to stress mitigation.

Table 1. Simulated pits.

\begin{tabular}{cccc}
\hline $\begin{array}{c}\text { Pit } \\
\text { Number }\end{array}$ & $\begin{array}{c}\text { Diameter } \\
\text { (inches) }\end{array}$ & $\begin{array}{c}\text { Depth } \\
\text { (inches) }\end{array}$ & $\begin{array}{c}\text { Separation from } \\
\text { Other Pits } \\
\text { (inches) }\end{array}$ \\
\hline 1 & 0.0313 & 0.0157 & 0.50 \\
2 & 0.0625 & 0.0313 & 0.50 \\
3 & 0.0938 & 0.0469 & 0.50 \\
\hline
\end{tabular}

Table 2. Side-drilled holes.

\begin{tabular}{ccccc}
\hline $\begin{array}{c}\text { Hole } \\
\text { Number }\end{array}$ & $\begin{array}{c}\text { Diameter } \\
\text { (inches) }\end{array}$ & $\begin{array}{c}\text { Distance from } \\
\text { Top Surface to } \\
\text { Centerline } \\
\text { (inches) }\end{array}$ & $\begin{array}{c}\text { Depth } \\
\text { (inches) }\end{array}$ & $\begin{array}{c}\text { Separation } \\
\text { from Other } \\
\text { Holes } \\
\text { (inches) }\end{array}$ \\
\hline 1 & 0.0625 & 0.0713 & 0.50 & 0.50 \\
2 & 0.0625 & 0.1113 & 0.50 & 0.50 \\
3 & 0.0625 & 0.1513 & 0.50 & 0.50 \\
\hline
\end{tabular}

For the visual inspection experiment, the same simulated pits machined for the eddy current evaluation were used as reference points. The variations in the textures are directly measured by the visual sensor. Therefore, comparison of the surface contours relative to the size of surface defects is the relevant metric. The targets in the base material area serve the purpose of a reference target for use in determining the system's response to a standard size target. The response of the system verifies the functionality of the system for comparison to the stress-mitigated material target.

No attempt was made at investigating effects near the base material weld crown interface, since weld geometries were different, and weld procedures and parameters that constructed the LP block were not known. Also, the LLNL block had the LP stress mitigation technique applied over its entire weld surface, so no relative comparison of weld surfaces before and after stress mitigation was possible.

One additional alteration was made to the LP block. The structure attached to support the block during welding was cut off to allow easier machining access to the bottom surface of the block. The effect was to the supporting structure of the block only and had no effect on experimental results.

\section{DATA AQUISITION}

\subsection{Ultrasonic Equipment and Data Acquisition Plan}

RDTech provided the equipment used for acquisition of ultrasonic data. Data acquisition was completed at RDTech's Huntersville, North Carolina facility, with assistance of RDTech personnel. The equipment is similar to the conceptual design for the Yucca Mountain Waste Package Closure System inspection system. The phased array hardware for driving the transducer and acquiring data was RDTech's Omniscan NX. The Omniscan is capable of using 16 array elements in each firing pattern. A 
water wedge, part WDGE-0054, was used to couple sound into the blocks. The wedge contained water that filled the apparatus with a continuous path of water between the transducer and a membrane made of a material having similar ultrasonic properties to water, low attenuation, and an operating range beyond the boiling point of water. This wedge was chosen for the experiments because it is the closest, immediately available probe to the conceptual design for the Yucca Mountain waste package closure cell inspection system. The primary difference in the existing wedge and the conceptual design is the absence of the water delivery and collection system. For the experiment purpose, a small amount of water was put onto the surface of the block under inspection to simulate the water delivery. The key factor was to use the same coupling mechanism planned for the actual system. The transducers attached to the wedge were RDTech 64 element $0.64-\mathrm{mm}$ pitch linear phased arrays. Transducers of two different frequencies were used, 2.25 Mhz (RDTech part 2L64-A2) and $5 \mathrm{Mhz}$ (RDTech part 5L64-A2). The data sets were displayed and captured postacquisition using RDTech Tomoview 2.2 software.

Data sets were acquired as the wedge was manually scanned across the surface of the blocks. Each scan was over both the stress-mitigated and base material target. A linear electronic (performed by the phased array) scan at a fixed angle was completed during the manual scan. The manual scan was done slow enough to ensure that the peak response from the notches could be located in the data. Details of the data acquired are shown in the figures of Appendix A. A scan across both targets in one pass minimized differences in any environmental, coupling, or other unknown factors in the comparison on the ultrasonic response to the stress-mitigated and base metal side targets. Precise triggering based on position encoders was not available. Maintaining a consistent velocity during the scan was attempted, but the transition between surface textures made this difficult. Repeated scans were made until a single scan included data for both targets. This ensured that the standard size base material target could be directly compared to the stress-mitigated target. Scans were completed on each block at several different angles of incidence and the two primary modes of ultrasonic wave propagation in solids (shear and longitudinal waves).

\subsection{Eddy Current Equipment and Data Acquisition Plan}

Eddy current measurements were performed using two different systems. The first was an INEEL laboratory system that mechanically raster scanned a single probe over the regions of interest. An orthogonally wound coil pair probe run in differential mode was used during scanning. The second was an RD Tech system that collected data via hand scanning with an array probe. Acquisition of data with RDTech eddy current array was completed at RDTech's Huntersville, North Carolina facility, with assistance from RDTech personnel. The array consisted of 18 elements having orthogonally wound coil pairs. During scanning, the individual elements were run in a transmit-receive mode. Although sensitive to pit defects, this mode of operation is intended to provide increased sensitivity to linear defects aligned parallel to the axis of the transmit coil. Unfortunately, unlike the differential mode, it suffers from increased sensitivity to liftoff and rough surface geometries.

Laboratory testing was performed at room temperature. Equivalent instrument settings were used for each test block, and the system/coils were nulled on defect-free areas of the test blocks before each scan. Raster scan rates were $0.12 \mathrm{in.} / \mathrm{sec} .(3 \mathrm{~mm} / \mathrm{sec}$.).

The specifics of the two systems employed are as follows:

INEEL Laboratory System

- $\quad$ Eddy current instrumentation: ZETEC MIZ 22

- $\quad$ Eddy current probe: ZETEC 3477-1-A Plus Point Probe (3-mm orthogonal wound coils, 50kHz$500 \mathrm{kHz}$ test range)

- Data acquisition software: Utex WinSpect 
- $\quad$ PC interface to eddy current instrumentation: Data Translation DataAcq EZ Board

- $\quad$ PC interface to X/Y linear stages: AT6400 Stepper Motor Indexer/Linear Amp Drivers

- $\quad$ Linear stages: Velmex Unislide (equipped with stepper motors and optical encoders)

\section{RD Tech System}

- $\quad$ Eddy current instrumentation: TC 7700

- Eddy current probe: RD Tech Prototype CRDM Probe E342118A (18 element array probe, $3 \times 3 \times 2 \mathrm{~mm}$ orthogonally wound coils; see attached RD Tech Documentation)

- Controlling software: RD Tech Eddy View.

\subsection{Visual Inspection Equipment}

Data for the visual inspection on the two blocks were acquired with a ServoRobotic's Flexcell with a mini-60 laser-profiling sensor. The sensor uses a projected plane of light and a camera to measure surface features along one line. The blocks were moved underneath the sensor to achieve a scan of the area around the simulated pits. The sensor was scanned over the simulated pits with a linear actuator set to travel at $300 \mathrm{~mm} / \mathrm{min}(11.8 \mathrm{in} . / \mathrm{min})$ with a Compumotor stepper motor controller and motors using linear slide as an actuator. The sample rate of the mini-60 is 30 frames per second, giving a spatial sampling frequency of 6 sample/mm (152.4 samples/in.). The direction of the light is determined by the standoff from the sensor and the camera resolution. For the two scans conducted, this resolution was about $0.1 \mathrm{~mm}$, or $10 \mathrm{sample} / \mathrm{mm}$ (254 samples/in.). The discrete measurement resolution of the surface elevation is less than $0.02 \mathrm{~mm}$ (0.0008 in.) (i.e., variations in depth of 1/1000 in. or more are measurable).

\section{TEST RESULTS AND DISCUSSION}

\subsection{Ultrasonic Inspection}

The experiments took advantage of the flexibility of the phased arrays by taking a linear scan at various angles to allow the peak signals to be located in postprocessing. The angle of incidence was set for each scan. Depth of focus was set to near the bottom of the block on the angle chosen. The hardware was set to scan that angle linearly across the bottom of the block, i.e., the same as raster-scanning a standard transducer. This eliminated one mechanical variable in the scan. The wedge was oriented to direct sound toward the target, and the wedge was manually (by hand of the operator) scanned across both the treated and nontreated target in a single scan. A straight edge was employed to keep the skew direction consistent and aid in the manual scan. The manual scans were completed at a deliberate rate such that several acquisitions were taken over the width of the target. The velocity of the scan was not precisely controlled. In postprocessing, the largest amplitude of ultrasonic reflection for each target was located from among all the scans. The magnitude of the reflections could then be compared between the base material and the stress-mitigated material on each block.

A variety of incident angles were applied to the blocks in the longitudinal wave mode. Shear waves were applied to the blocks at a 45-degree angle. Table 3 shows the difference in relative magnitude between the two stress-mitigation techniques. There is a balance between keeping the frequency low enough to penetrate the large-grained material with enough energy to detect a target and having a wavelength short enough to respond effectively to small targets. The transducers available for these experiments were 2.25 and $5 \mathrm{Mhz}$. To get an appropriate wavelength for each mode of sound propagation, the 2.25-Mhz transducer was employed for the shear wave (approximate sound speed of $2.8 \mathrm{~mm} / \mu \mathrm{S}$ ), and $5 \mathrm{Mhz}$ was used for the longitudinal wave (approximate sound speed of $5.2 \mathrm{~mm} / \mu \mathrm{S}$ ). In the actual system, a transducer with frequency between those used for this experiment may be used to allow use of shear and longitudinal waves from the same transducer. 
The amplitude of the peak-rectified ultrasonic signal from the targets in the stress mitigated side (Asm) and the amplitude of the base material side (Ab) are compared in decibel change (D) in the expression:

$\mathrm{D}=20 \log _{10}(\mathrm{Asm} / \mathrm{Ab})$.

A negative value reflects a decrease in amplitude in the stress-mitigated target signal compared to the target signal from the base material. To arrive at a difference between the two blocks, the decreases are compared with $\mathrm{R}=\mathrm{D}_{\mathrm{LP}}-\mathrm{D}_{\mathrm{PB}}$, where subscripts are added to $\mathrm{D}$ to indicate which block is being referenced. $\mathrm{D}_{\mathrm{LP}}$ is the difference in the laser peening sample block; $\mathrm{D}_{\mathrm{PB}}$ is the difference in the controlled plasticity burnishing sample block; and $\mathrm{R}$ is the difference between them. $\mathrm{R}$ is negative when the $\mathrm{LP}$ block has a larger attenuation than the PB block. Table 3 summarizes the results. Appendix A of this report, Figures A-1 through A-4, shows the details of the scans.

Table 3. Results of ultrasonic comparison.

\begin{tabular}{|c|c|c|c|c|c|}
\hline \multirow{2}{*}{$\begin{array}{l}\text { Angle of } \\
\text { Incidence } \\
\text { (degree) }\end{array}$} & \multirow{2}{*}{$\begin{array}{c}\text { Frequency } \\
(\mathrm{Mhz})\end{array}$} & \multirow{2}{*}{$\begin{array}{l}\text { Propagation } \\
\text { Mode }\end{array}$} & \multicolumn{2}{|c|}{$\begin{array}{l}\text { Percentage Difference in } \\
\text { Peak Amplitude Difference }\end{array}$} & \multirow{2}{*}{$\begin{array}{c}\text { Result } \\
\mathrm{Y}=\text { significant difference } \\
\mathrm{N}=\text { no significant difference }\end{array}$} \\
\hline & & & LP & $\mathrm{PB}$ & \\
\hline 45 & 2.25 & Shear & $-0.11 \mathrm{~dB}$ & $+0.78 \mathrm{~dB}$ & $\mathrm{~N},-0.89 \mathrm{~dB}$ \\
\hline 45 & 5 & Longitudinal & $+0.61 \mathrm{~dB}$ & $0.0 \mathrm{~dB}$ & $\mathrm{~N},+0.61 \mathrm{~dB}$ \\
\hline 60 & 5 & Longitudinal & $-0.31 \mathrm{~dB}$ & $+1.16 \mathrm{~dB}$ & $\mathrm{~N},-1.47 \mathrm{~dB}$ \\
\hline 70 & 5 & Longitudinal & $-0.66 \mathrm{~dB}$ & N/A* & $\mathrm{N}^{*}$ \\
\hline
\end{tabular}

*The PB block was not long enough to scan the target at 70 degrees. The difference in the stress-mitigated area versus the base material in the LP block was not significant.

The resulting comparisons show a very small difference between the two surface preparations when compared either against the base material or the normalized relative comparison. The difference between the response of the stress-mitigated and base material areas of the LP block ranged from +0.61 to $-0.66 \mathrm{~dB}$ for the various angles and modes. The conclusion is that the base surface and stress-mitigated surface for the LP block show no distinguishable preference. That difference falls within the range of expected variation for an ultrasonic scan. The difference between the responses of the stress-mitigated and base material area of the PB block ranged from +1.16 to $0.0 \mathrm{~dB}$ for the various angles and modes. This also is a very small difference. The consistently positive difference toward the stress-mitigated area may show a small preference for the very smooth surface obtained in the PB stress mitigation process. The largest relative response difference $(1.47 \mathrm{~dB})$ is not significant in our opinion for this application.

\subsection{Eddy Current Inspection}

\subsubsection{Simulated Pits}

Raster scans were performed at three test frequencies: 400, 240, and $50 \mathrm{kHz}$. A number of frequencies were used to vary eddy current skin depth (depth at which the amplitude of the eddy currents drop to $1 / \mathrm{e}$ of its value at the surface). Assuming constant electrical conductivity and magnetic permeability, skin depth will increase as test frequencies are lowered. Increasing the skin depth will distribute more of the eddy currents deeper into the test material, thereby reducing sensitivity to surface/near surface variations and geometry. Unfortunately, this also reduces sensitivity to surface defects, yet often a test frequency can be found that will minimize unwanted surface condition responses while still having adequate sensitivity to defects. Figure 6 presents a collection of the images obtained for the two different mitigation test blocks. The images in the figure all have mitigated regions on their lower half and pit sizes running left to right, ranging from largest to smallest. Appendix B presents detailed 
images and test parameters. These high-resolution scans were produced using data collection steps of 0.010 in. $(0.25 \mathrm{~mm})$ with raster steps of $0.20 \mathrm{in} .(0.5 \mathrm{~mm})$. The vertical and horizontal line traces provided with the images center on the 0.063 -in. pit in the mitigated region of the test blocks.

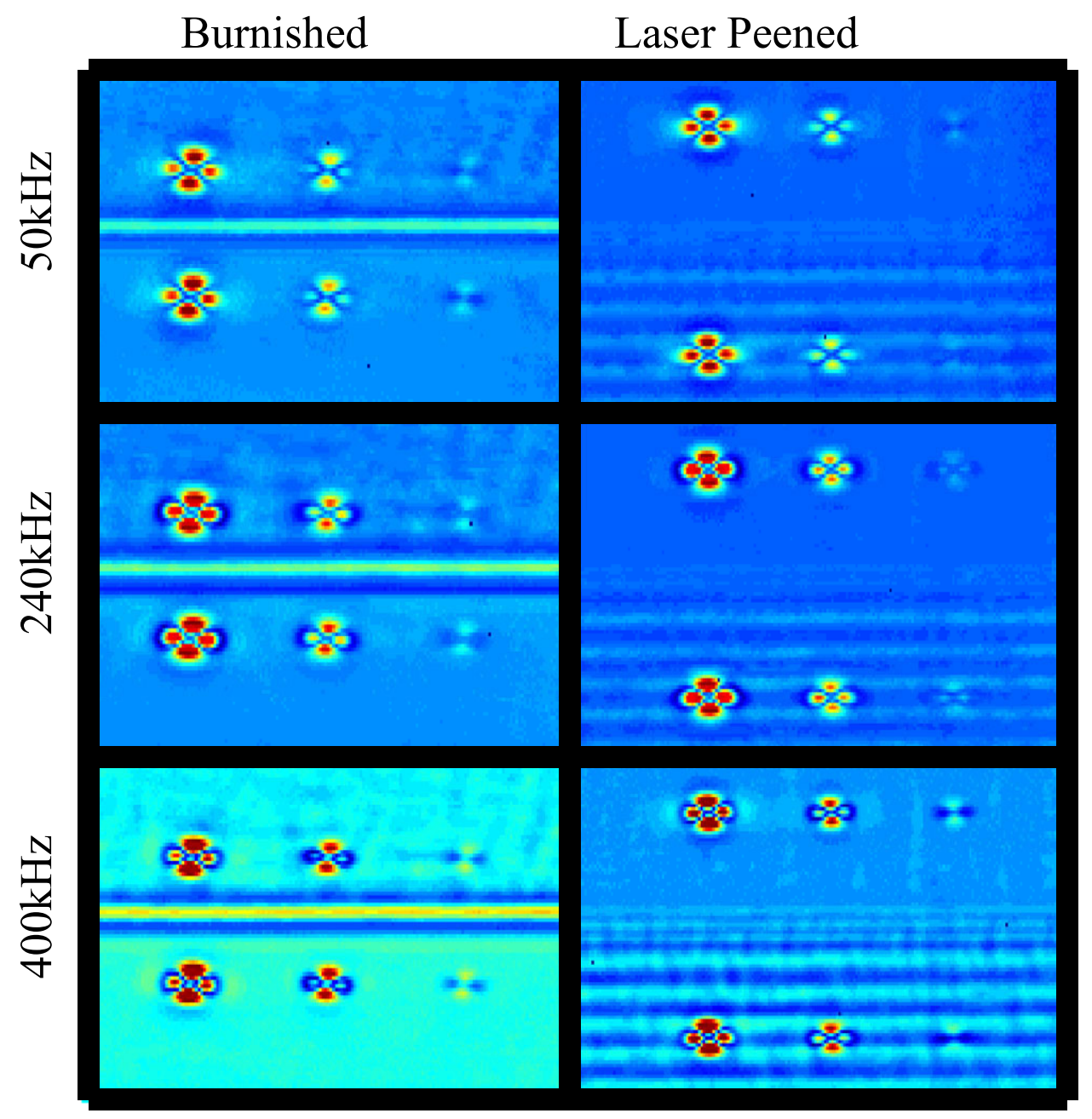

Figure 6. Eddy current raster scans of stress mitigation test blocks.

Hand scanning with an array probe was also performed at 200 and $400 \mathrm{kHz}$ using RD Tech instrumentation. Due to the nature of hand scanning and the probe used (18 staggered coils, $3 \mathrm{~mm}$ $\times 3 \mathrm{~mm}$, with center-to-center spacing of about $1.5 \mathrm{~mm}$ ), these scans have significantly less spatial resolution and repeatability than those collected at INEEL. However, the results represent a commercial array system. Figure 7 is a screen print from the RD Tech system showing a typical scan result. The $\mathrm{red} / \mathrm{blue}$ indications are the responses from the two largest pits in each area. The $\mathrm{x} / \mathrm{y}$ curser in the image is over the 0.063 -in. pit in the burnished region of the test block. The weak responses of the smallest pits in the series are not obvious in the image but can be found with the curser. Appendix B presents the RD Tech scans.

As a means to quantitatively compare the results, the magnitudes of the responses for the 0.063 -in. pits and background noise were extracted from the scans to calculate signal-to-noise ratios. This information is summarized in Table 4. Note that the values of the noise contain two basic contributions: electrical and material noise. The noise was measured by taking a "peak-to-peak" value of signal magnitudes over an area. Effort was taken to select a measurement area away from the pit responses and 
one with no unusual isolated noise spikes. However, the measurement areas used were of sufficient size to include contributions from material variations. This is stated to point out that the LP areas have significant material noise contributions compared to the unmitigated and $\mathrm{PB}$ regions.

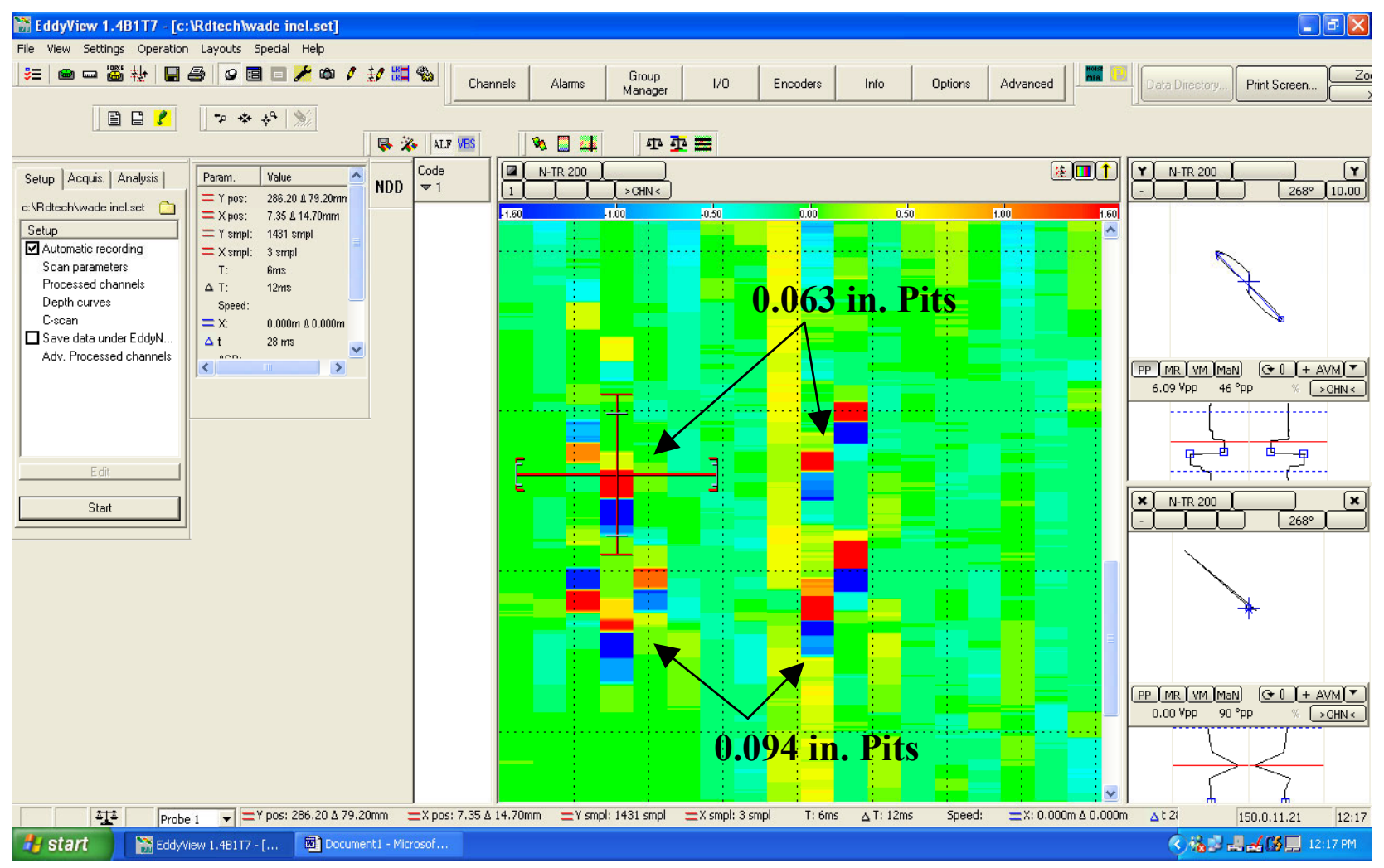

Figure 7. RD Tech scan of PB test block at $400 \mathrm{kHz}$. The burnished section is on the left side of the image.

Table 4. Signal-to-noise ratios for 0.063-in. pits.

\begin{tabular}{|c|c|c|c|c|c|}
\hline $\begin{array}{c}\text { Stress Mitigation } \\
\text { Process }\end{array}$ & ET System & $\begin{array}{l}\text { Frequency } \\
\qquad(\mathrm{kHz})\end{array}$ & $\begin{array}{l}\text { 1/16-in. } \\
\text { Pit Signal } \\
\text { (volts*) }\end{array}$ & $\begin{array}{l}\text { Noise } \\
(\text { volts*) }\end{array}$ & $\begin{array}{c}\text { Signal-to-Noise } \\
\text { Ratio }\end{array}$ \\
\hline \multicolumn{6}{|c|}{ Unmitigated Surface } \\
\hline \multirow[t]{5}{*}{ PB Block } & \multirow{3}{*}{$\begin{array}{l}\text { ZETEC MIZ } 22 \\
\text { 3479-1-A Probe }\end{array}$} & 400 & 1.22 & 0.12 & 10.17 \\
\hline & & 240 & 1.11 & 0.08 & 13.9 \\
\hline & & 50 & 0.90 & 0.08 & 10.0 \\
\hline & \multirow{2}{*}{$\begin{array}{l}\text { RD Tech TC } 7700 \\
\text { CRDM Array Probe }\end{array}$} & 400 & 5.57 & 0.47 & 11.9 \\
\hline & & 200 & 1.20 & 0.20 & 6.0 \\
\hline \multirow[t]{5}{*}{ LP Block } & \multirow{3}{*}{$\begin{array}{l}\text { ZETEC MIZ } 22 \\
\text { 3479-1-A Probe }\end{array}$} & 400 & 1.22 & 0.06 & 20.3 \\
\hline & & 240 & 1.00 & 0.02 & 50.0 \\
\hline & & 50 & 0.58 & 0.04 & 14.5 \\
\hline & \multirow{2}{*}{$\begin{array}{l}\text { RD Tech TC } 7700 \\
\text { CRDM Array Probe }\end{array}$} & 400 & 2.28 & 0.05 & 45.6 \\
\hline & & 200 & 1.26 & 0.16 & 7.9 \\
\hline
\end{tabular}




\begin{tabular}{llcccc}
\hline $\begin{array}{c}\text { Stress Mitigation } \\
\text { Process }\end{array}$ & \multicolumn{1}{c}{ ET System } & $\begin{array}{c}\text { Frequency } \\
(\mathrm{kHz})\end{array}$ & $\begin{array}{c}\text { 1/16-in. } \\
\text { Pit Signal } \\
(\text { volts*) }\end{array}$ & $\begin{array}{c}\text { Noise } \\
(\text { volts } *)\end{array}$ & $\begin{array}{c}\text { Signal-to-Noise } \\
\text { Ratio }\end{array}$ \\
\hline PB Block & Mitigated Surface & & \\
& ZETEC MIZ 22 & 400 & 1.21 & 0.05 & 24.2 \\
& 3479-1-A Probe & 240 & 1.20 & 0.05 & 24.0 \\
& RD Tech TC 700 & 400 & 6.09 & 0.12 & 50.7 \\
& CRDM Array Probe & 200 & 1.46 & 0.07 & 20.9 \\
\hline LP Block & ZETEC MIZ 22 & 400 & 1.24 & 0.28 & 4.42 \\
& 3479-1-A Probe & 240 & 1.03 & 0.14 & 7.36 \\
& & 50 & 0.81 & 0.11 & 7.36 \\
\cline { 2 - 6 } & RD Tech TC 7700 & 400 & 1.87 & 0.16 & 11.7 \\
& CRDM Array Probe & 200 & 0.73 & 0.06 & 12.2 \\
\hline
\end{tabular}

*Amplitude of voltage recorded is system-dependent.

The basic trends observed are that, when compared to the unmitigated surfaces, the BP process increases the signal-to-noise ratio while the LP process decreases the ratio. Figure 8 illustrates that both processes produce a distinct shift in the electrical conductivity of the surfaces mitigated, i.e., the base response shifts up (decrease in conductivity) in the mitigated regions. However, due to the uniformity of the PB process and resulting smooth surface finish, material noise is reduced, but in the LP region the coarse raster steps and resulting surface roughness produce significant local variations. This imparts significant material noise into the eddy current signal for the LP process.

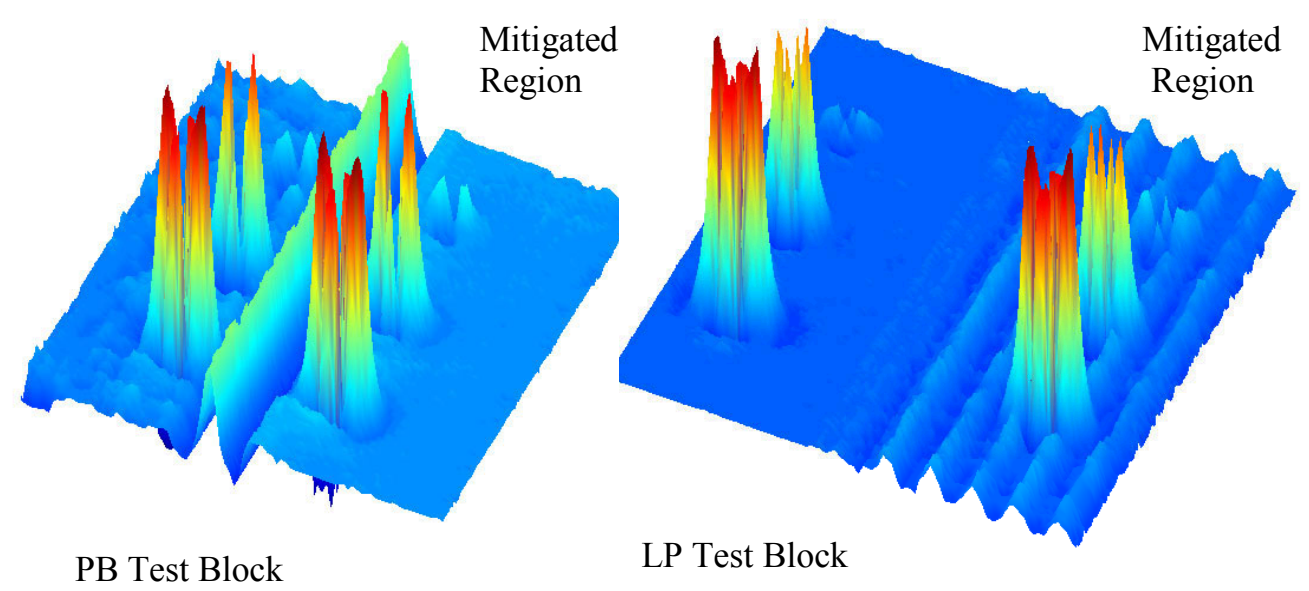

Figure 8. Surface plots of the raster scans collected at $240 \mathrm{kHz}$ for the two mitigation test blocks. Equivalent instrument settings were used for both scans. 
Although there are measurable differences between the two processes, neither process prevents detection of 0.063-in. surface/near-surface defects. Defect sizing is also a requirement, and it is impacted by the quality of the measured defect response. The material texture imparted by the LP process makes defect sizing less accurate. The signal components that can be used for defect sizing are amplitude, phase, and their spatial distribution. Local distortions of these components by baseline material variations will affect how the defects are sized. For example, if only signal amplitude is used to define the length of a linear defect such as a crack or diameter of a large pit that significantly exceeds the dimensions of the test coils, a local shift up or down in amplitude at the edge of a defect will predict an increase or decrease in defect dimension, respectively. A very rough estimate of the possible error can be made based on the physical size and rate of change for the spatial variations encountered. In the $240-\mathrm{kHz}$ raster scan of the LP area, there is an average peak-to-peak noise level of 0.14 volts. The major contributor to this noise is the material variation that peaks over a 0.08 -in. $(2-\mathrm{mm})$ distance transverse to the raster direction. The \pm 0.07 -volt noise then translates into a possible error of \pm 0.04 in. $(1 \mathrm{~mm})$ in defining the edge of the defect. Note that this error could be reduced by additional signal processing steps to extract predictable/nonrandom variations in the baseline signal. Analysis techniques would need to be developed for implementation. Measurement error along the raster direction is reduced due to less material variation. Of more interest for this application, in which the critical size defect is about the same size as the test coils to be used, is that peak amplitude will likely be used to initially determine defect size. In this case, baseline signal variations can add or subtract to the peak response to yield false or missed calls when they are near the amplitude threshold set for the critical size flaw. Additional signal analysis would be required to mitigate the problem. As with the other case, these analysis techniques would need to be developed for implementation. The amount of noise reduction will be ill-defined until signal processing techniques are developed and tested. The spatially uniform 0.05 -volt peak-to-peak noise measured in the PB region will make defect sizing much less challenging and more accurate.

\subsubsection{Side-Drilled Holes}

Raster scans were performed over the location of the side-drilled holes at $50 \mathrm{kHz}$, the lowest recommended test frequency for the 3479-1-A Probe. A 50-kHz test frequency yields a skin depth of about 0.094 in. $(2.4 \mathrm{~mm})$ in alloy 22 . As a result, sensitivity to the deeper holes will be significantly reduced compared to the hole located 0.063 in. below the surface. Figures 9 and 10 show images from the raster scans. The scans start at the very edge of the blocks and move inward. Edge effects mask any results until the probe is $0.158 \mathrm{in}$. $(4 \mathrm{~mm})$ from the edge. Scans were performed with data collection steps of 0.010 in. $(0.25 \mathrm{~mm})$ and raster steps of 0.020 in. $(0.5 \mathrm{~mm})$. Also note, for the PB block, scanning was performed in two directions. This results in opposite coils sensing the holes, thereby producing a 180-degree shift in the defect response seen between the unmitigated and mitigated sections of the test block. The images indicate that only the two side-drilled holes nearest to the top surface can be detected, and the second deepest hole ( $0.80 \mathrm{in} . / 2.0 \mathrm{~mm}$ from the surface) detected only marginally.

The reduced signal-to-noise ratios for the unmitigated region of the PB block and the mitigated region of the LP block further diminish the responses, thereby making detection even less reliable. 

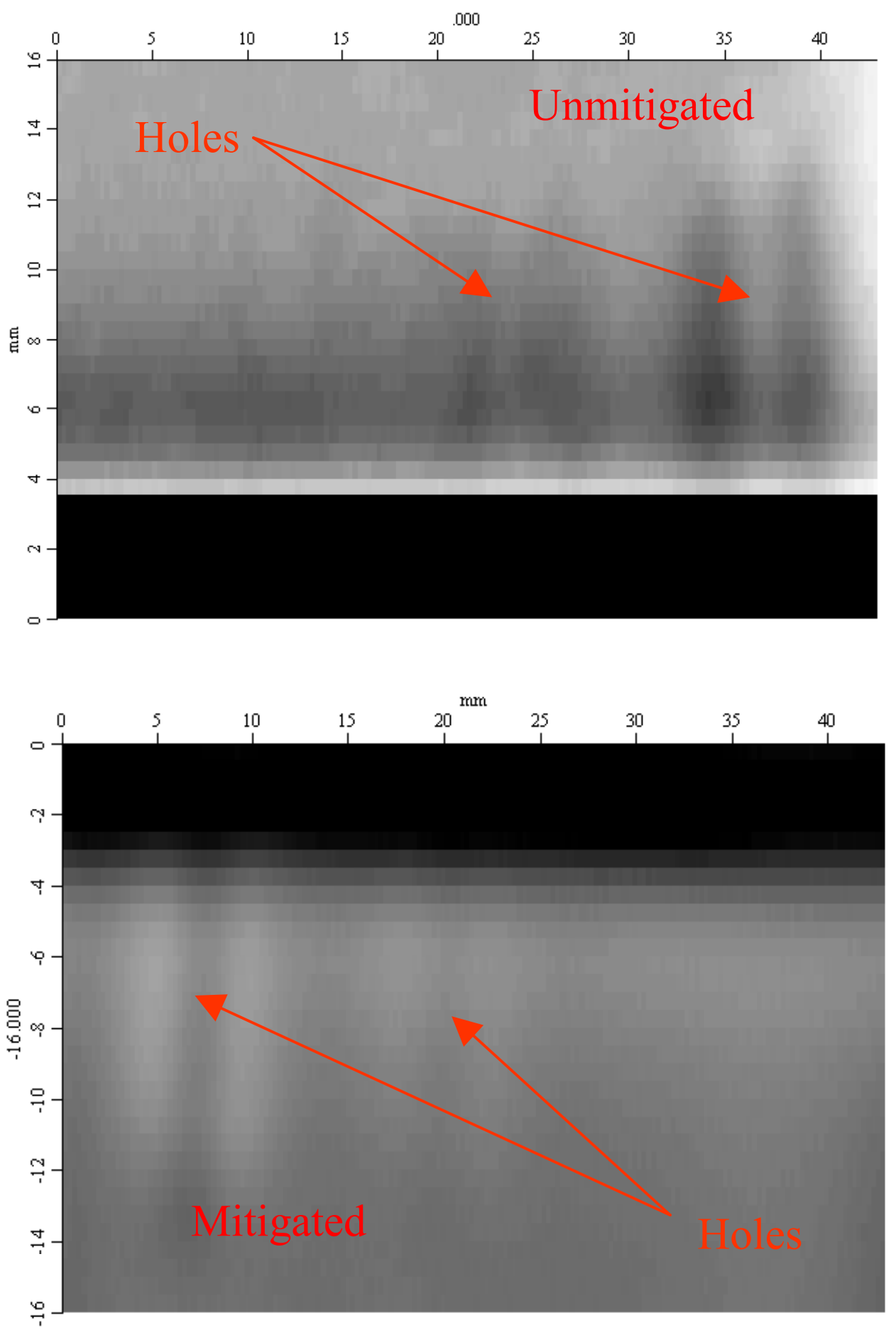

Figure 9. Raster scans over the side-drilled holes in the low plasticity burnished test block. Only the two side-drilled holes nearest to the top surface can be detected. 


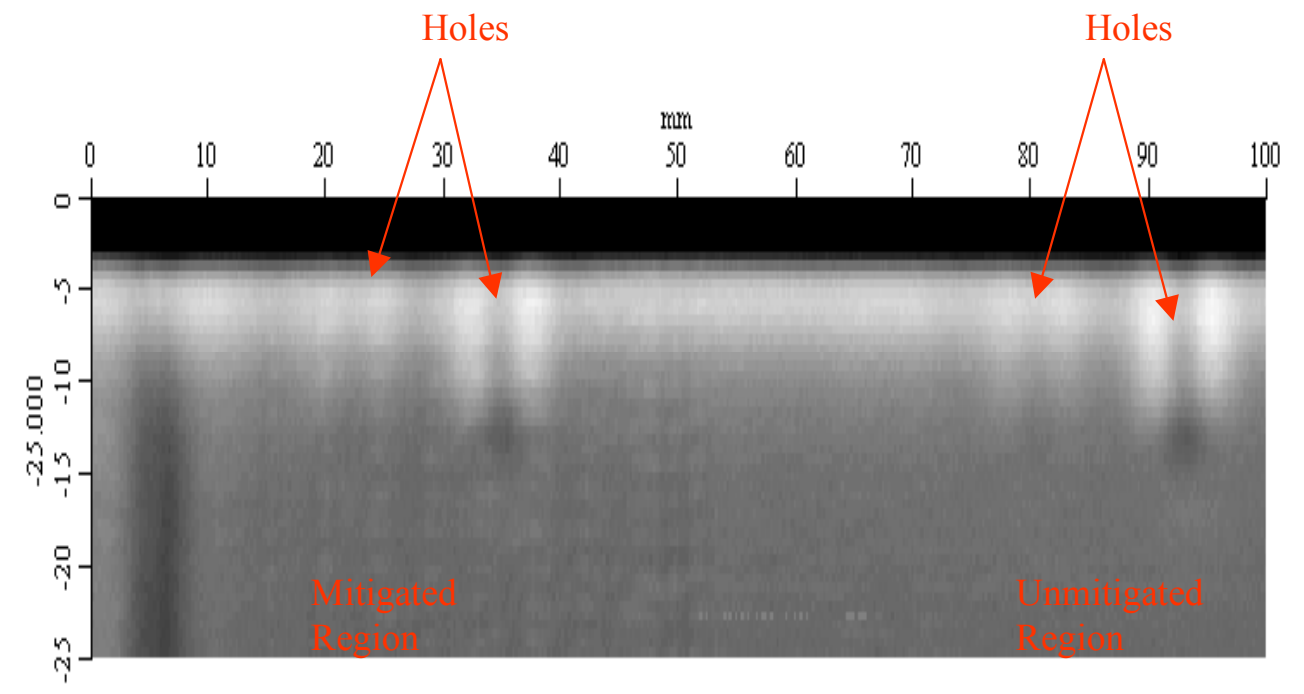

Figure 10. Raster scan over the side-drilled holes in the LP block. Only the two side-drilled holes nearest to the top surface can be detected.

\subsection{Visual Inspection}

Typical profiles across stress mitigated and base material areas of each block are shown in Figure 11. The elevation change from adjacent peaks and valleys in the surface contour is considered the appropriate measurement. The elevation change in the LP block is typically larger than the PB block. This is apparent even in the photographs in Figures 1 and 2. A typical variation for the LP block is 0.009 in.; a typical variation in the PB block is 0.006 in., as shown in Figure 11. Compared to the smallest reference pit ( 0.0157 in. deep), both surfaces as measured by the visual sensor would have a significant percentage of error in depth measurement. For the detection requirement of 0.063 in., the error in measurement of depth of a contour in the LP texture could be as high as $+14 \%$ if a local peak in the texture were measured as part of a surface pore. The error in measurement of the depth in the PB plate would be $10 \%$. The base material measures as much as a 0.04 -in. variation, giving a $6 \%$ variation. There is a measurable difference in the effect of the two types of stress mitigation methods for the visual inspection system. The sizing of flaws is diminished by 0.009 in. However, it is clear from the worst-case stress mitigated LP block, shown in Figure 11e, there is no apparent issue with detecting a pit even one-half the critical flaw size.

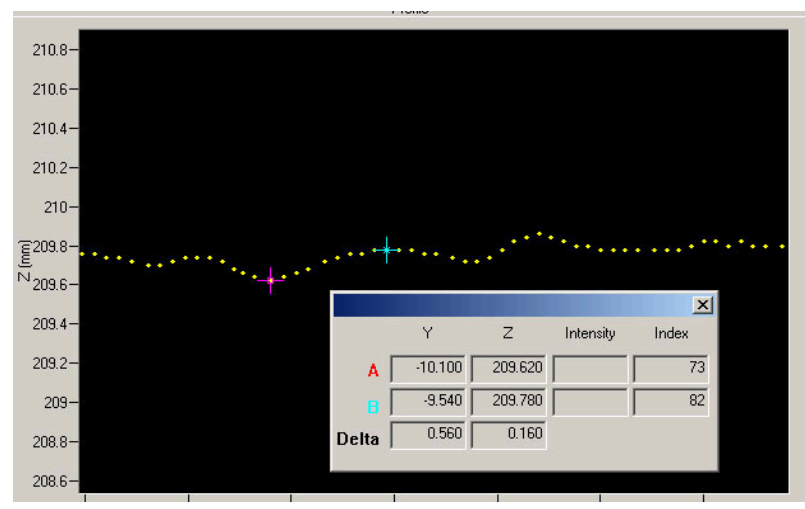

(a) Stress-mitigated PB sample block.

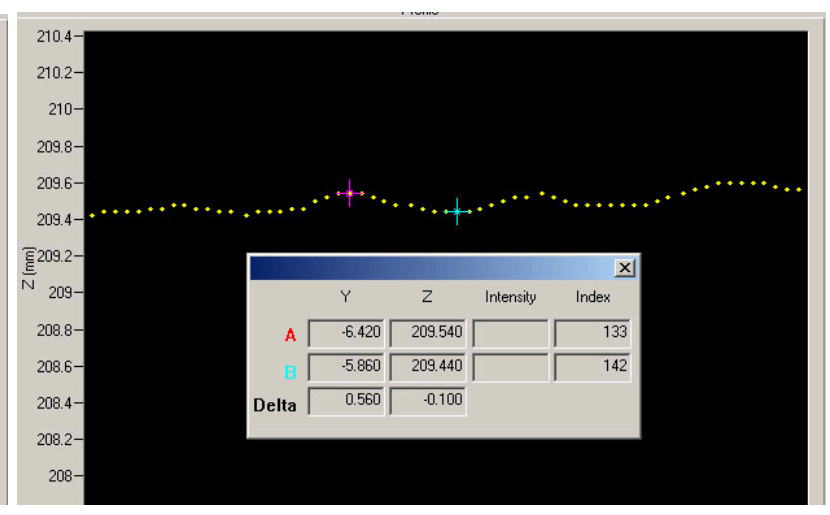

(b) Base material PB sample block. 


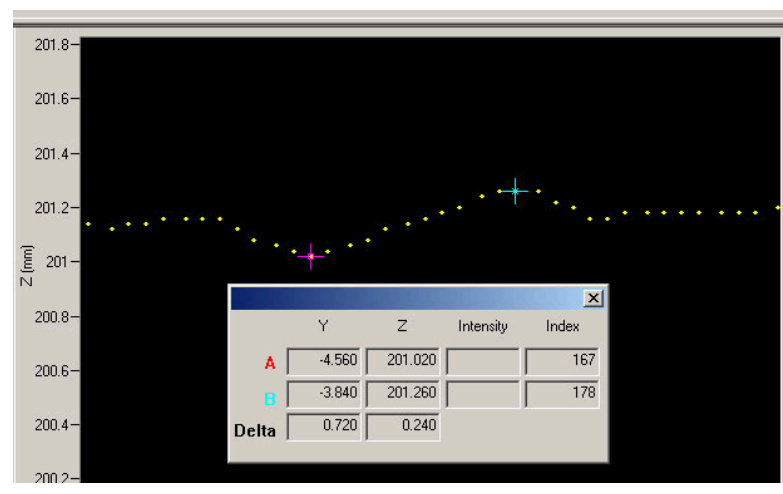

(c) Stress-mitigated LP sample block.

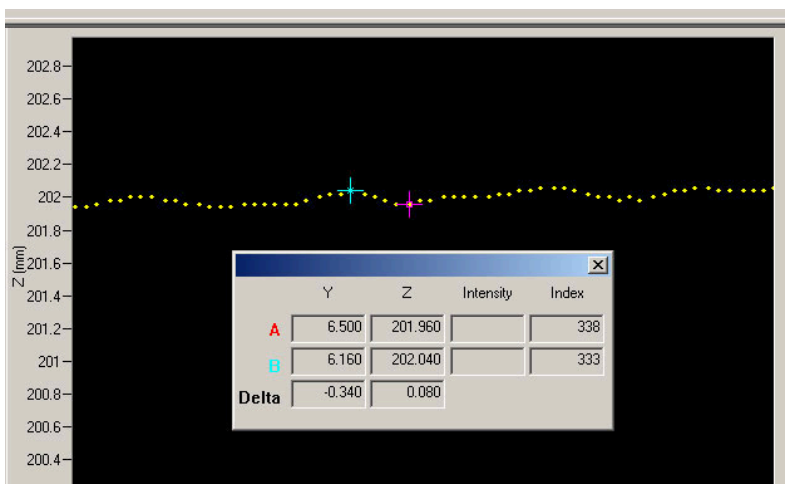

(d) Base material LP sample block.

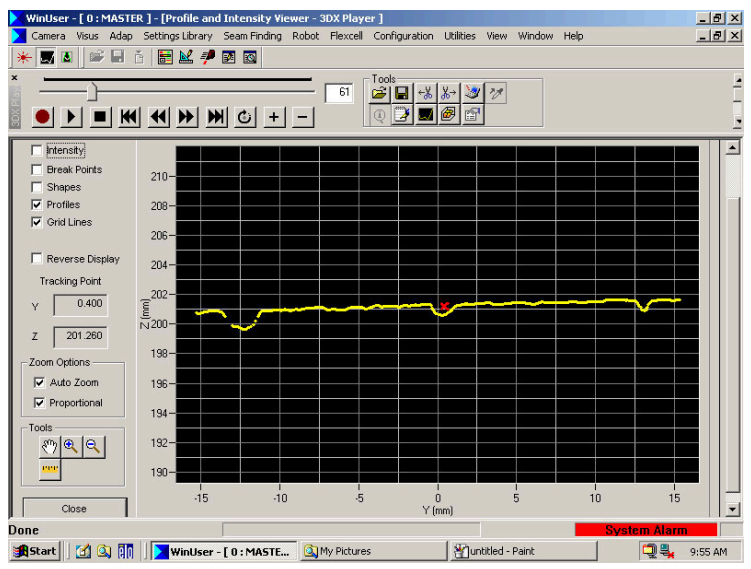

(e) Stress-mitigated LP block with reference pits (worst case).

Figure 11. Profile measured across a typical profile of each section of the blocks and the worst case LP with the reference pits. The maximum surface variations from adjacent peaks and valleys were $0.16 \mathrm{~mm}$ (0.006 in.) on the PB block and $0.24 \mathrm{~mm}(0.009 \mathrm{in}$.) on the LP block. The maximum surface variation on the base material was $0.10 \mathrm{~mm}$ (0.004 in.). Profiles of the reference pits are shown for the LP stressmitigated surface.

A rendering of data from scans of the two blocks is shown in Figure 12. It is obvious from this presentation that detection of the smallest pit in the block is not compromised by either stress mitigation technique. A regular 0.031-in.-diameter pit is easily detected on both mitigated surfaces.

An additional observation contrasting the surface finishes produced by the two surfaces is that, in general, a highly reflective surface can cause an issue with the laser-based profile measurement. In the case of a fillet weld, a butterfly effect can be observed. A duller surface finish is optimal in such a case; see Appendix $\mathrm{C}$ for an example. However, for a flat surface, such as the outer lid weld, the effect has not been observed to cause a problem. 


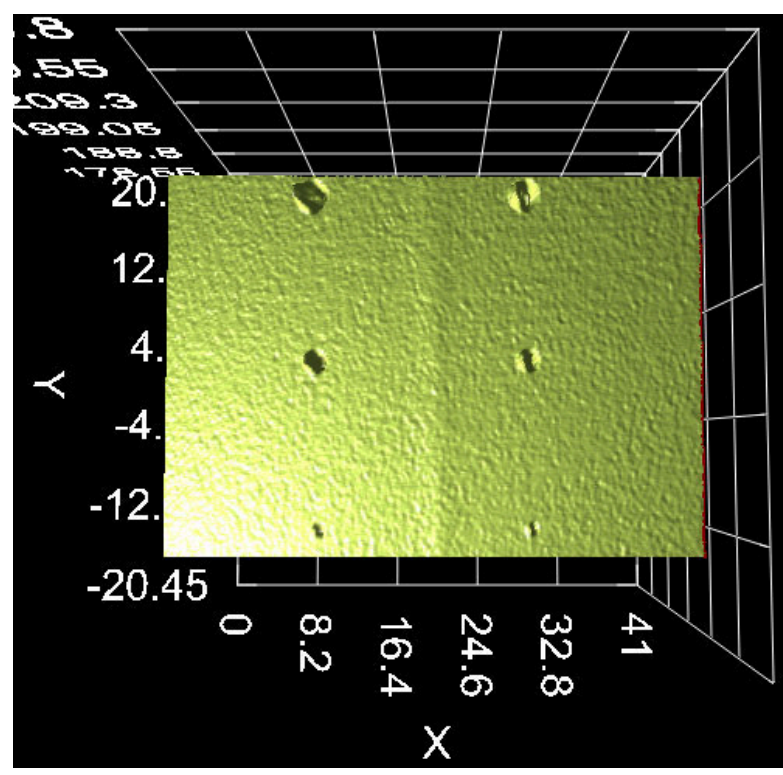

(a) PB visual inspection.

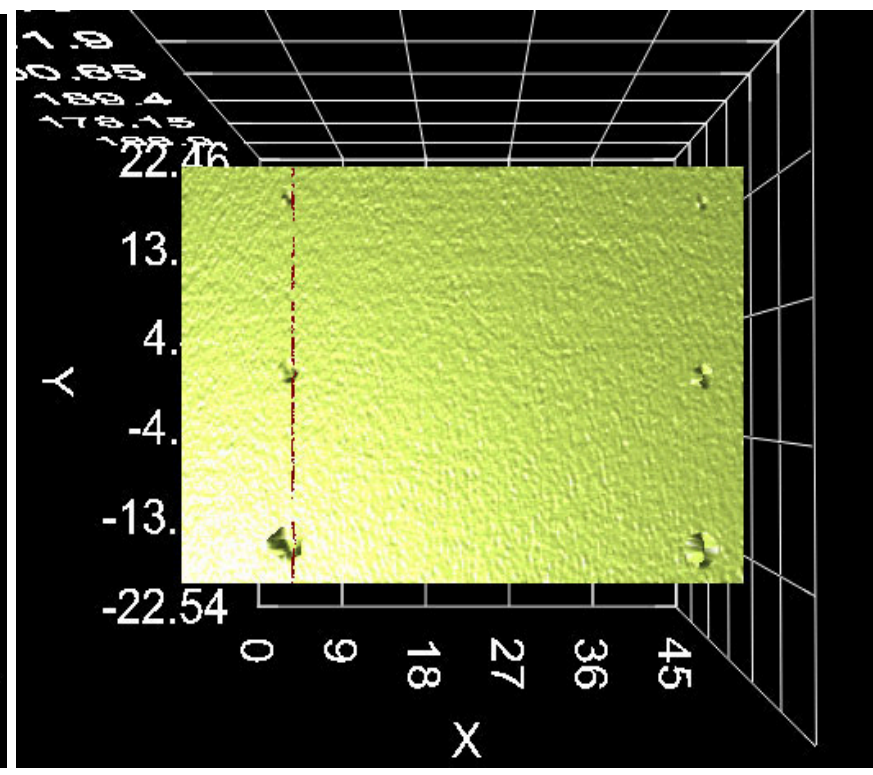

(b) LP visual inspection.

Figure 12. Simulated pits on each of the sample blocks scanned by the Servo Robotics laserprofiling sensor. The stress-mitigated area is on the left in each of the scans.

\section{CONCLUSIONS AND RECOMMENDATIONS}

\subsection{Limited Sample Set}

The following conclusions and recommendations are based on the results obtained from a limited sample set, i.e., one LP sample and one PB sample. We assume that the material and physical modifications that resulted in the test blocks are typical of the two processes. If changes in processing steps result in different material or physical attributes, caution should be used in applying these results. Significant variations in process and resulting material property could invalidate the results and conclusions presented in this report.

\subsection{Ultrasonic Inspection}

The ultrasonic experiments performed and described in this report show an insignificant difference in the response from targets in the two types of stress-mitigated materials. A maximum difference of $1.46 \mathrm{~dB}$ is not significant; thus, from an ultrasonic inspection point of view, neither surface provides an adverse condition for coupling of sound into the part using the technique and material specified in the conceptual design for the Yucca Mountain waste package. The surface created by the low plasticity burnishing technique provides a smooth surface that causes only a very small increase in coupling efficiency, even compared to the base material. From our ultrasonic testing considerations, the resulting small difference does not offer a compelling argument for choosing one technique over the other.

An issue observed when moving the probe over the transitions from the stress-mitigated area to the base material leads to a recommendation relevant to both methods. The surface of the stress-mitigated area should be extended beyond the extent of the probe's mechanical interface with the surface, or be tapered to facilitate the interface of the probe and uninterrupted coupling of ultrasound into the metal. 
In sum,

- Based on the results, the difference in ultrasonic response is insufficient to recommend one stressmitigation technique over the other

- $\quad$ Transitions from stress-mitigated to base material in the area near the weld where the probes will reside must be eliminated or ameliorated by tapering the transition.

\subsection{Eddy Current Inspection}

The ability to detect the minimum 0.063 -in. flaw is not impacted by either process, but we believe that defect-sizing capabilities will be reduced by the LP process compared to the PB process. The reduced sizing capability will result from the local variations in electrical conductivity in the base material created by the spatially coarse pattern of application for the LP process. The material variations add background noise to the eddy current response, thereby decreasing the signal-to-noise ratio. Even though detection of a 0.063 -in. critical flaw is not strongly impacted, the decreased signal to noise will reduce sizing accuracy, thereby increasing the risk of having false or missed calls. The increased number of false or missed calls that may result cannot be predicted at this time due to the limited number of samples and defects evaluated. The PB process does produce a similar shift in surface electrical conductivity to that of the LP process, but the spatial distribution is sufficiently fine as to appear as a uniform change in the base material. If viable, applying the LP process using a similar spatial distribution would mitigate the defectsizing problem. If LP is selected as the mitigation process to be implemented, we recommend that a fine spatial distribution be used.

In sum,

- Neither process significantly affects the ability to detect 0.063 -in. defects.

- The coarse raster steps of the LP process impart a local variation in the eddy current baseline signal that, without additional signal processing steps or alteration in the spatial distribution of the laser peening, will affect defect sizing capabilities, thereby increasing the potential for false and missed calls. The magnitude of the problem cannot be fully defined at this time.

- Applying signal processing techniques may potentially be used to mitigate the variability in the baseline response for the LP process, but they are atypical for the eddy current technique and will need to be developed for this application. The inherent risk associated with the development of signal processing techniques is that a complete and/or unique solution may not be found for the problem.

- Decreasing the raster scan step size for the LP process will help to mitigate defect-sizing problems.

- The PB process does not suffer from the coarse material variations seen in the LP process that affect the eddy current baseline signal. The results in fact indicate that an improved signal-to-noise ratio is obtained after the $\mathrm{PB}$ process has been applied to the base material. In general, an increase in signal-to-noise ratio will improve defect-sizing capabilities. The very smooth surface produced by the process will also reduce probe wear during scanning.

\subsection{Visual Inspection}

The visual inspection data on the two blocks show only small differences between the two stress mitigation surfaces. The smallest of the simulated pit targets is easily distinguished from the background of the surrounding surface and is more than 10 times deeper than the maximum ripple measured by the visual sensor in either the LP or PB stress-mitigated area. The larger ripple in the surface will affect the sizing of the defect. Measurement of the depth of a surface contour can have an error of 0.009 in. due to the surface contour of the LP surface. The difference in measured variation between the two surfaces is 
only 0.003 in. A strong recommendation cannot be made based on this result. In general, a duller surface of the LP block is preferable to a highly reflective surface of the PB block for this type of sensor; however, in this application, without acute angles a preference for the surface preparation is not apparent.

In sum,

- The difference in visual inspection results is insufficient to base a recommendation of one stressmitigation technique over the other. 
Appendix A

\section{Ultrasonic Details}




\section{Appendix A}

\section{Ultrasonic Details}

The amplitude data used to obtain the results in Table 3 was obtained from the scan results shown in Figures A1-A4. The amplitudes were applied to the formulas in Section 4.1 to calculate the resultant values. These figures are screen shots of the data from the scans on each of the blocks in Table 3. The peak response from each target was found by placing a cursor in the Tomoview 2.2 program. The result is annotated in the screen capture above each of the profile peeks. The images shown in the figures A1-A4 are the plan view images of the ultrasonic response with the y-axis representing depth into the block and the $\mathrm{x}$-axis representing the scan across both targets. The varying dimension in the width (x-axis dimension) in some results is due to inconsistent scan velocity between scans. Precise triggering based on position encoders was not available. An attempt to maintain a consistent velocity during the scan was made, but the transition between surface textures made this difficult. Repeated scans were made until a single scan included data for both targets. The comparison is between the peak amplitude response between the stress mitigated target and the base material in each; therefore, this variation is not important to the comparison method.

Figures A-1, A-2, A-3, and A-4 show peak amplitudes in the gated region around the targets with respect to the $\mathrm{x}$-axis position of the probe. Amplitudes are easily found in the profile. Tomoview software merges data from the linear scan into a side view. The peak amplitude versus the $\mathrm{x}$-axis is show in the profile shown above the side view. The peak amplitude for each target is taken from the profile.

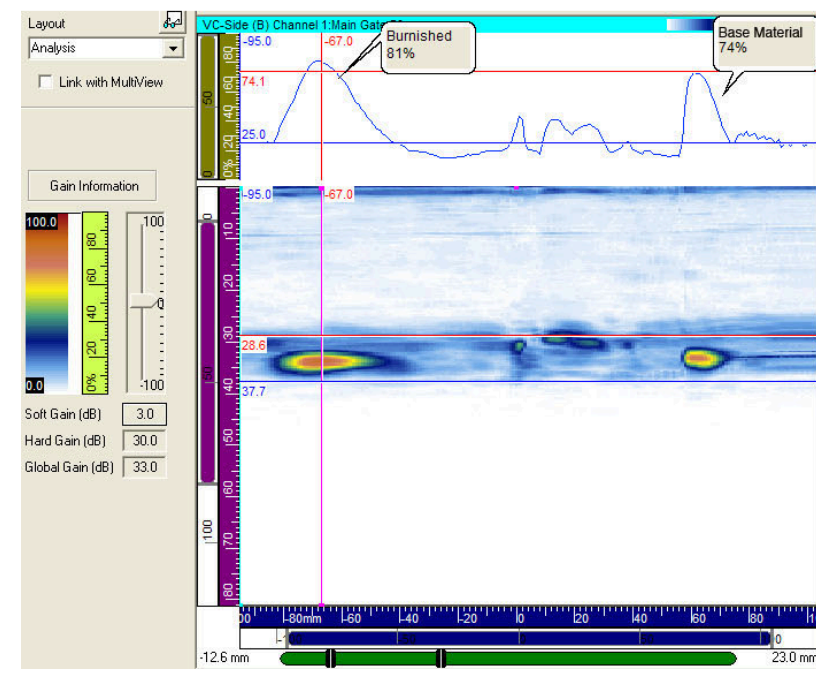

(a) PB 45-degree sheer.

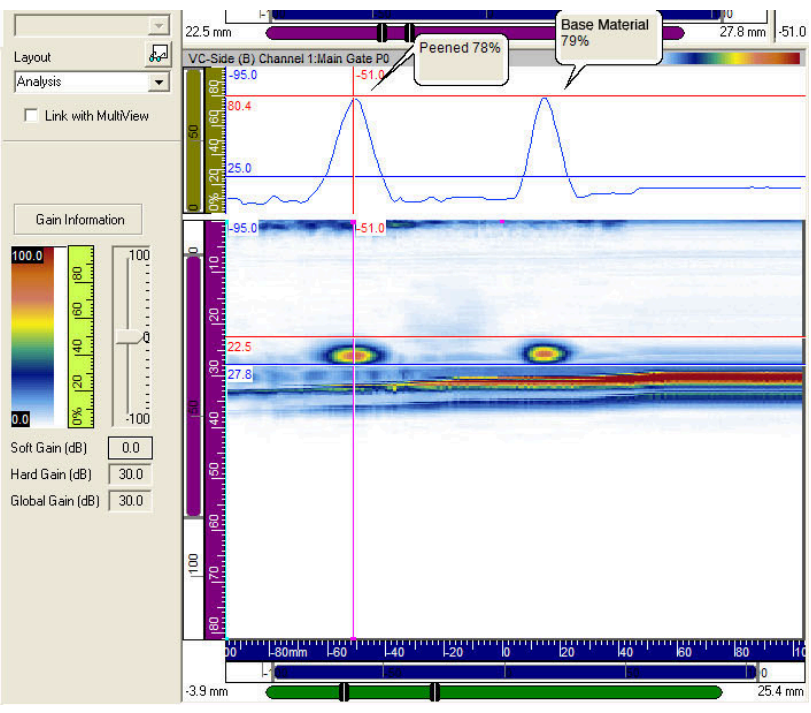

(b) LP 45-degree sheer.

Figure A-1. Resulting side view of ultrasonic scans for the blocks for a 45-degree sheer wave. The y-axis corresponds to depth in the block. The $\mathrm{x}$-axis corresponds to motion of the wedge crossing over targets in the base and the stress-mitigated materials. The stress-mitigated target is on the left in each of the scans. The profile shown above the image is the peak amplitude on the scan in the region of the targets. The measured peak values for the PB block, shown in (a), are $74 \%$ base material and $81 \%$ stress-mitigated material. The measured peak values for the LP block, shown in (b), are $79 \%$ base material and $78 \%$ stress-mitigated material. This results in $\mathrm{D}_{\mathrm{LP}}=-0.11 \mathrm{~dB}, \mathrm{D}_{\mathrm{PB}}=+0.78 \mathrm{~dB}$, and $\mathrm{R}=-0.89 \mathrm{~dB}$. 


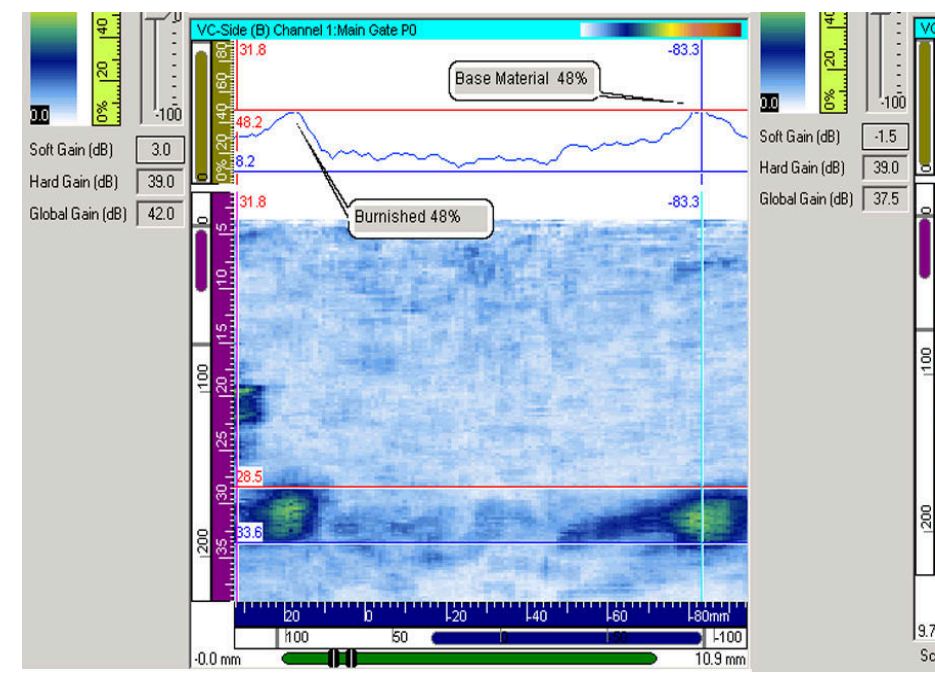

(a) PB 45-degree longitudinal.

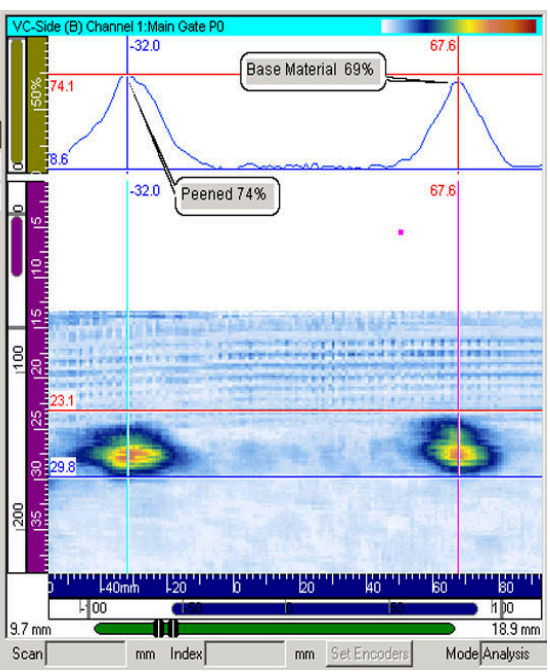

(b) LP 45-degree longitudinal.

Figure A-2. Resulting side view of ultrasonic scans for the blocks for a 45-degree longitudinal wave. The $\mathrm{y}$-axis corresponds to depth in the block. The x-axis corresponds to motion of the wedge crossing over targets in the base and stress mitigated materials. The stress-mitigated target is on the left in each of the scans. The profile shown above the image is the peak amplitude on the scan in the region of the targets. The measured peak values for the controlled PB block, shown in (a), are $48 \%$ base material and $48 \%$ stress-mitigated material. The measured peak values for the LP block, shown in (b), are $69 \%$ base material and $74 \%$ stress-mitigated material. This results in $\mathrm{D}_{\mathrm{LP}}=+0.61 \mathrm{~dB}, \mathrm{D}_{\mathrm{PB}}=+0.0 \mathrm{~dB}$, and $\mathrm{R}=+0.61 \mathrm{~dB}$.

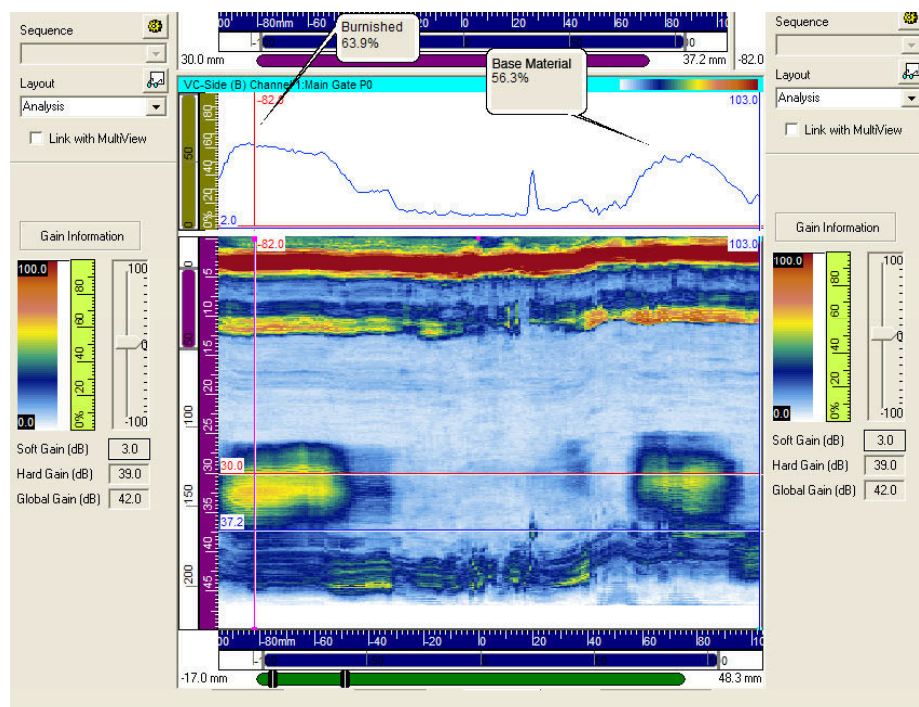

(a) PB 60-degree longitudinal.

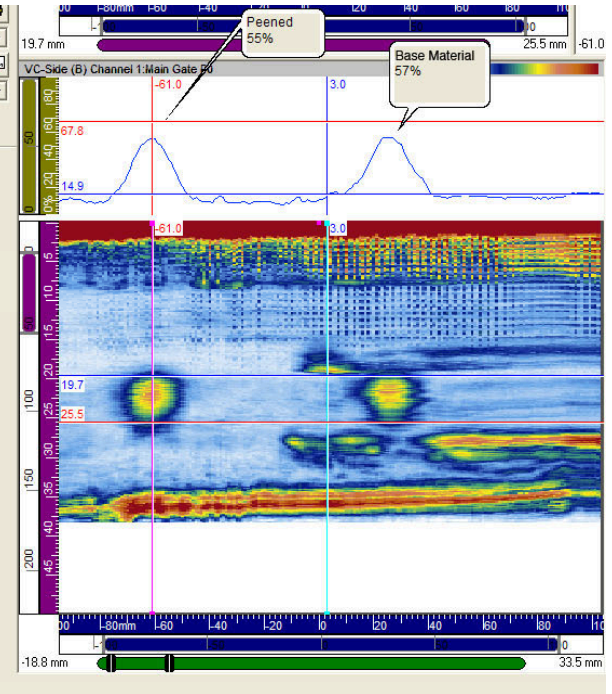

(b) LP 60-degree longitudinal.

Figure A-3. Resulting side view of ultrasonic scans for the blocks for a 60-degree longitudinal wave. The $y$-axis corresponds to depth in the block. The x-axis corresponds to motion of the wedge crossing over targets in the base and stress-mitigated materials. The stress-mitigated target is on the left in each of the scans. The profile shown above the image is the peak amplitude on the scan in the region of the targets. The profile shown above the image is the peak amplitude on the scan in the region of the targets. The measured peak values for the PB block, shown in (a), are 56\% base material and $64 \%$ stress-mitigated material. The measured peak values for the LP block, shown in (b), are 57\% base material and 55\% stress-mitigated material. This results in $\mathrm{D}_{\mathrm{LP}}=-0.31 \mathrm{~dB}, \mathrm{D}_{\mathrm{PB}}=+1.16 \mathrm{~dB}$, and $\mathrm{R}=-1.47 \mathrm{~dB}$. 


\section{No data available for burnish block at $70^{\circ}$}

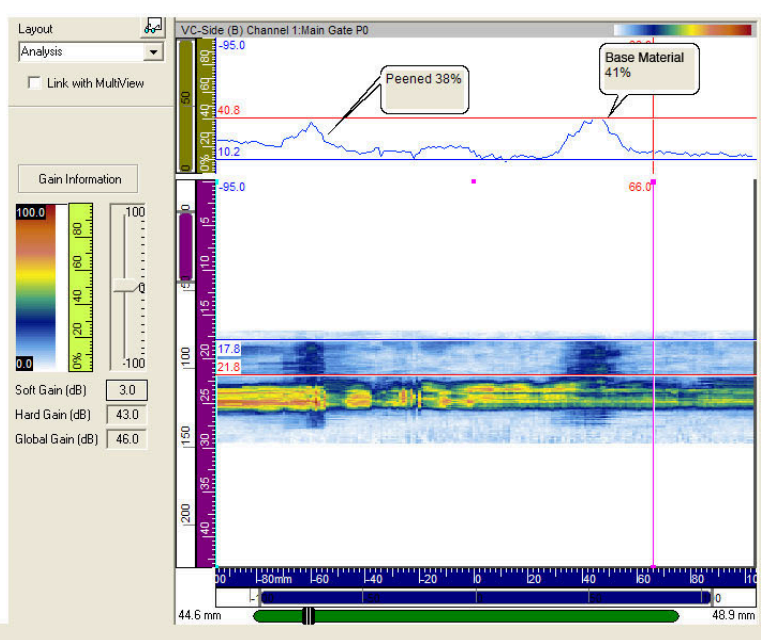

(a) PB 70-degree longitudinal (not available).

(b) LP 70-degree longitudinal.

Figure A-4. Resulting side plan view of ultrasonic scan for the blocks for a 70-degree longitudinal wave for the LP block. The y-axis corresponds to depth in the block. The x-axis corresponds to motion of the wedge crossing over targets in the base and the stress mitigated materials. The stress-mitigated target is on the left in the scan. The profile shown above the image is the peak amplitude on the scan in the region of the targets. The profile shown above the image is the peak amplitude on the scan in the region of the targets. The measured peak values for the LP block, shown in (b), are $41 \%$ base material and 38\% stressmitigated material. This results in $\mathrm{D}_{\mathrm{LP}}=-0.66 \mathrm{~dB}$. The PB block was not long enough to successfully scan the targets at this angle. No comparison data to the PB block are available. 


\section{Appendix B Detailed Eddy Current Results}




\section{Appendix B}

\section{Detailed Eddy Current Results}

This appendix presents the detailed images generated during raster scanning of the two mitigation test blocks using a single element probe. With each image are the ZETEC instrument settings and data collection step/raster sizes used to acquire the data, and screen captures of the data collected during hand scanning using the RD Tech instrumentation and an 18-element array probe. The data associated with

these images were used to obtain the signal-to-noise ratios summarized in Table 4, "signal-to-noise ratios for 0.063 -in. pits." 


\section{Burnished $400 \mathrm{kHz}$}

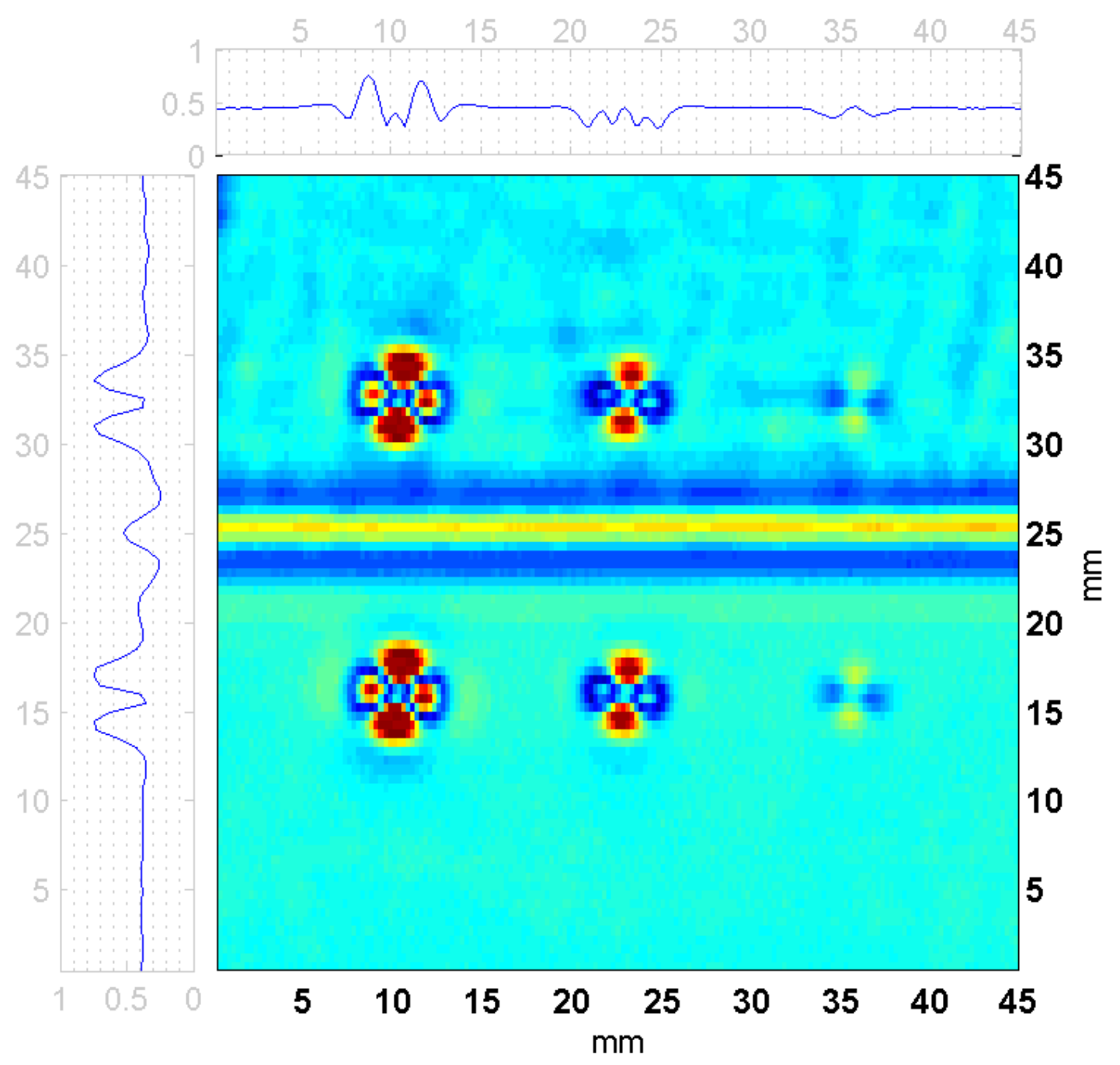

Figure B-1.

Sample:

PB Block

Mitigated Region: Lower half

Instrument:

ZETEC MIZ 22

Probe:

ZETEC 3479-1-A Plus Point (run in differential mode)

Scan Size: $\quad 45 \mathrm{~mm} \times 45 \mathrm{~mm}$

X Step Size: $\quad 0.25 \mathrm{~mm}$

Y Step Size: $\quad 0.50 \mathrm{~mm}$

Test Frequency: $\quad 400 \mathrm{kHz}$

Gain $26 \mathrm{~dB}$

$\mathrm{V} / \mathrm{H}: \quad 8 / 8$

Phase: $\quad 25$ degrees 


\section{Burnished 240kHz}

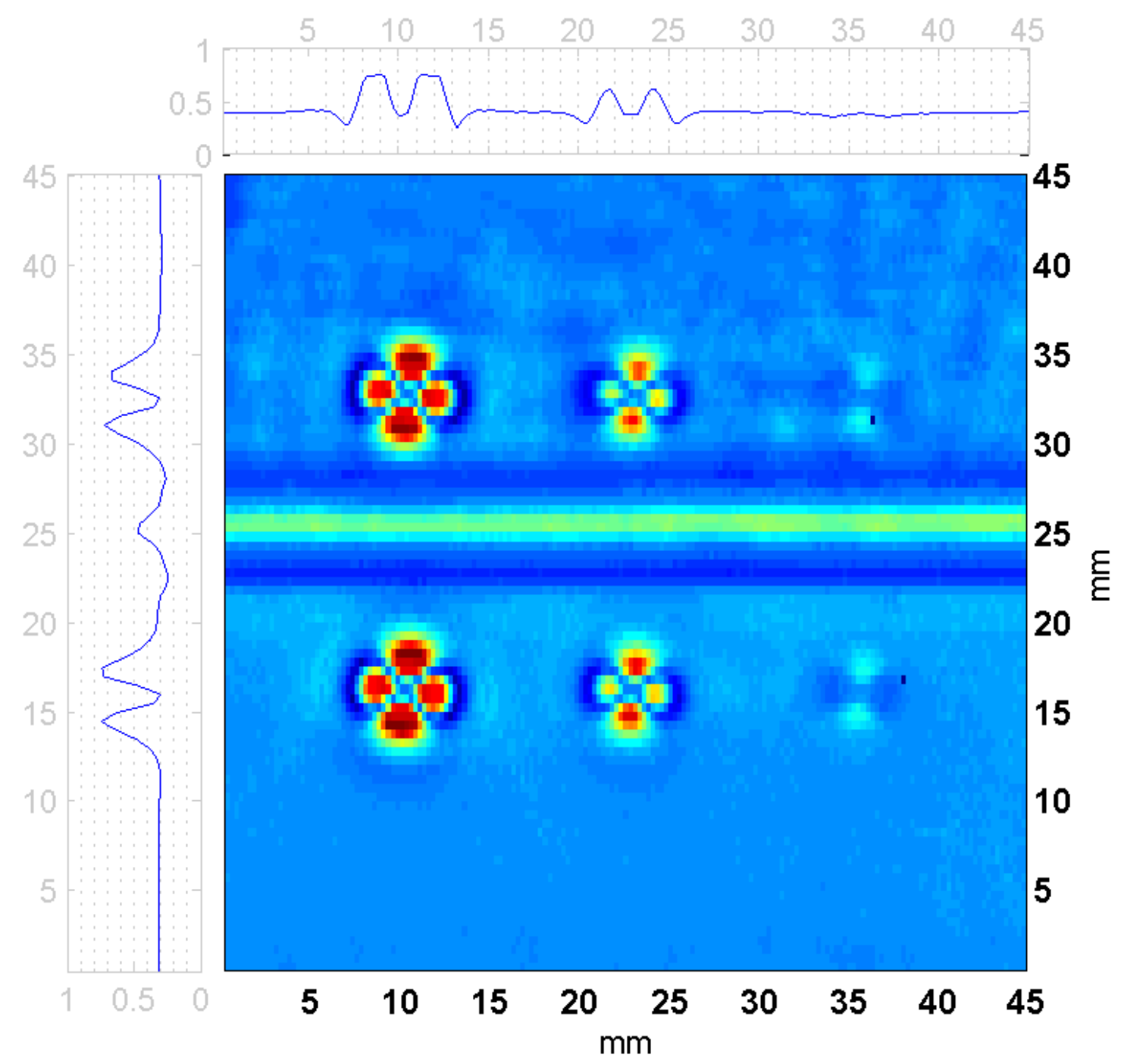

Figure B-2.

Sample:

PB Block

Mitigated Region: Lower half

Instrument:

ZETEC MIZ 22

Probe:

ZETEC 3479-1-A Plus Point (run in differential mode)

Scan Size:

$45 \mathrm{~mm} \times 45 \mathrm{~mm}$

X Step Size: $\quad 0.25 \mathrm{~mm}$

Y Step Size: $\quad 0.50 \mathrm{~mm}$

Test Frequency: $240 \mathrm{kHz}$

Gain: $\quad 26 \mathrm{~dB}$

$\mathrm{V} / \mathrm{H}: \quad 8 / 8$

Phase: $\quad 0$ degrees 


\section{Burnished $50 \mathrm{kHz}$}

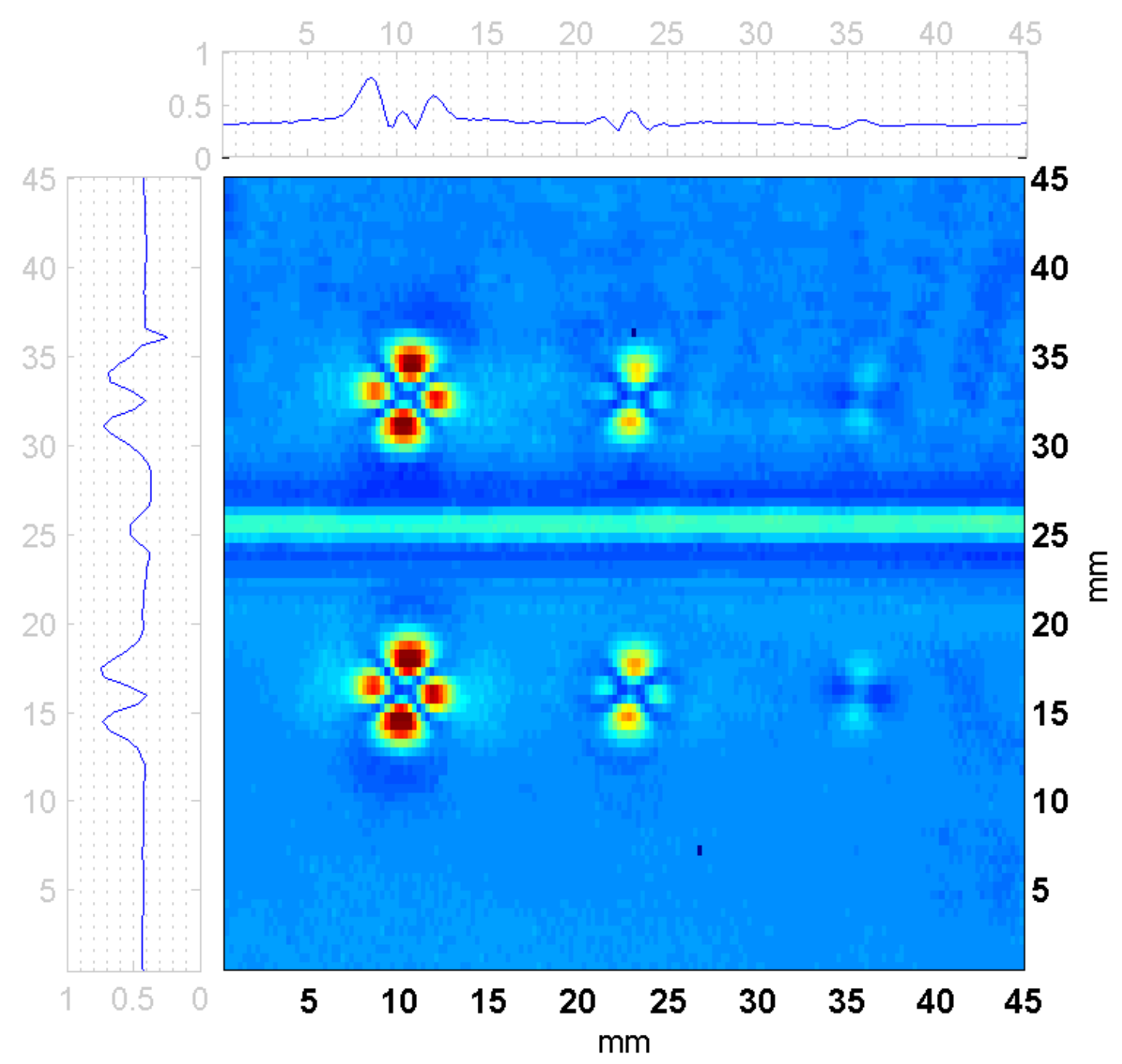

Figure B-3.

Sample:

PB Test Block

Mitigated Region: Lower half

Instrument: $\quad$ ZETEC MIZ 22

Probe: $\quad$ ZETEC 3479-1-A Plus Point (run in differential mode)

Scan Size: $\quad 45 \mathrm{~mm} \times 45 \mathrm{~mm}$

X Step Size: $\quad 0.25 \mathrm{~mm}$

Y Step Size: $\quad 0.50 \mathrm{~mm}$

Test Frequency: $\quad 50 \mathrm{kHz}$

Gain: $\quad 36 \mathrm{~dB}$

V/H: $\quad 8 / 8$

Phase: $\quad 294$ degrees 


\section{Laser $400 \mathrm{kHz}$}

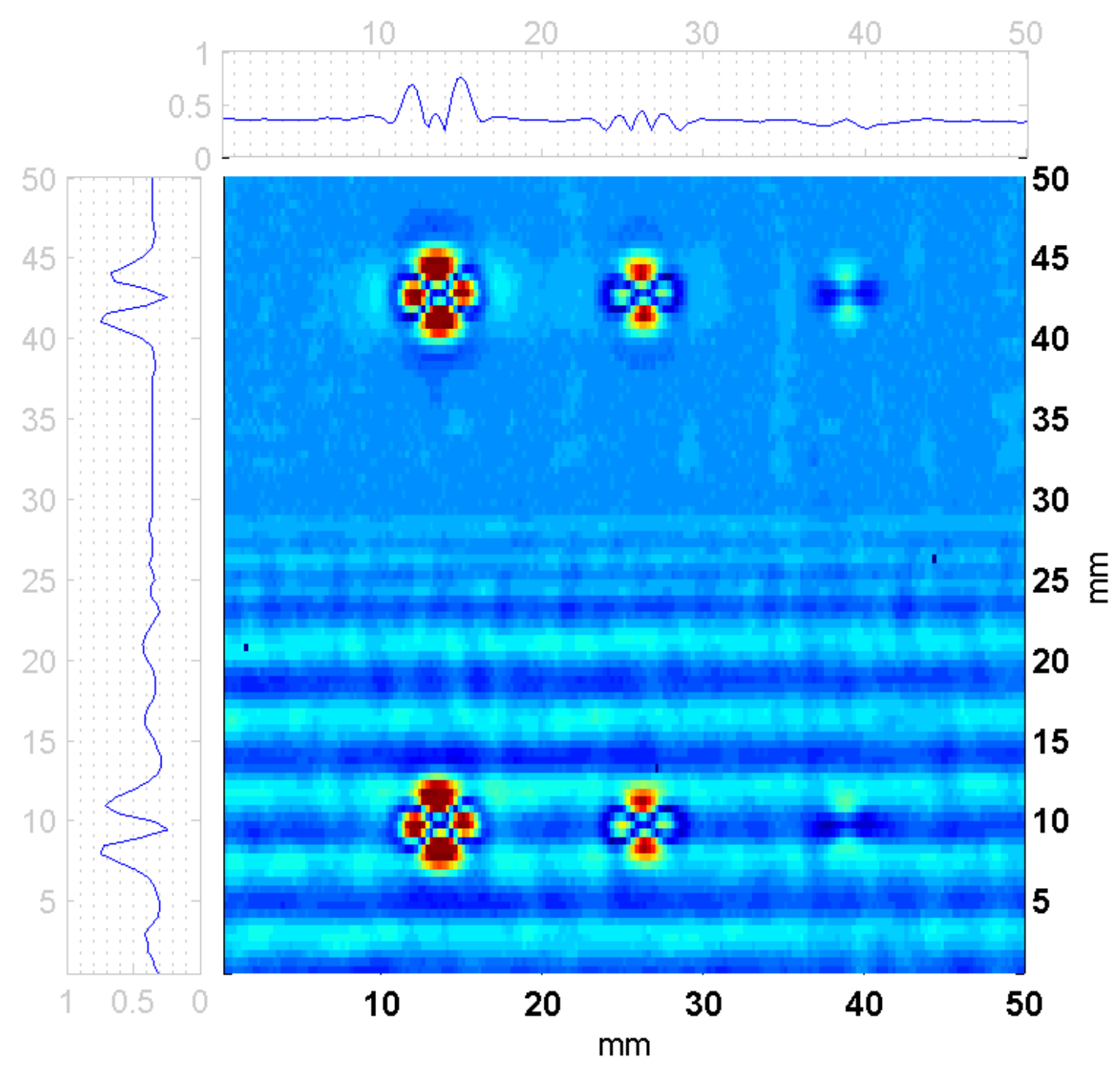

Figure B-4.

Sample: $\quad$ LP Block

Mitigated Region: Lower half

Instrument: $\quad$ ZETEC MIZ 22

Probe: $\quad$ ZETEC 3479-1-A Plus Point (run in differential mode)

Scan Size: $\quad 50 \mathrm{~mm} \times 50 \mathrm{~mm}$

X Step Size: $\quad 0.25 \mathrm{~mm}$

Y Step Size: $\quad 0.50 \mathrm{~mm}$

Test Frequency: $\quad 400 \mathrm{kHz}$

Gain: $\quad 26 \mathrm{~dB}$

V/H: $\quad 8 / 8$

Phase: $\quad 25$ degrees 


\section{Laser $240 \mathrm{kHz}$}

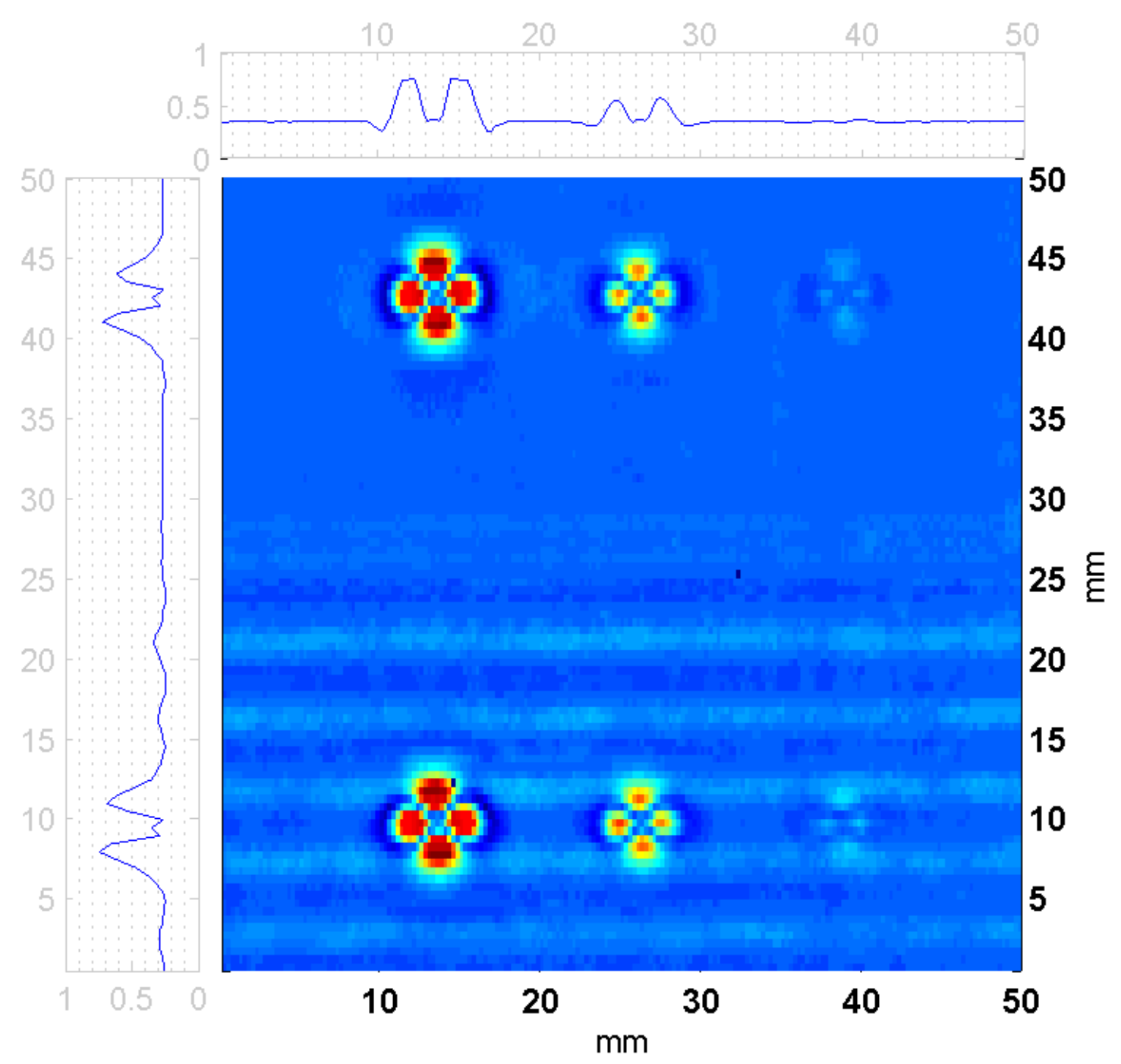

Figure B-5.

Sample:

LP Block

Mitigated Region: Lower half

Instrument:

ZETEC MIZ 22

Probe:

ZETEC 3479-1-A Plus Point (run in differential mode)

Scan Size: $\quad 50 \mathrm{~mm} \times 50 \mathrm{~mm}$

X Step Size: $\quad 0.25 \mathrm{~mm}$

Y Step Size: $\quad 0.50 \mathrm{~mm}$

Test Frequency: $240 \mathrm{kHz}$

Gain: $\quad 26 \mathrm{~dB}$

V/H: $\quad 8 / 8$

Phase: $\quad 0$ degrees 


\section{Laser $50 \mathrm{kHz}$}

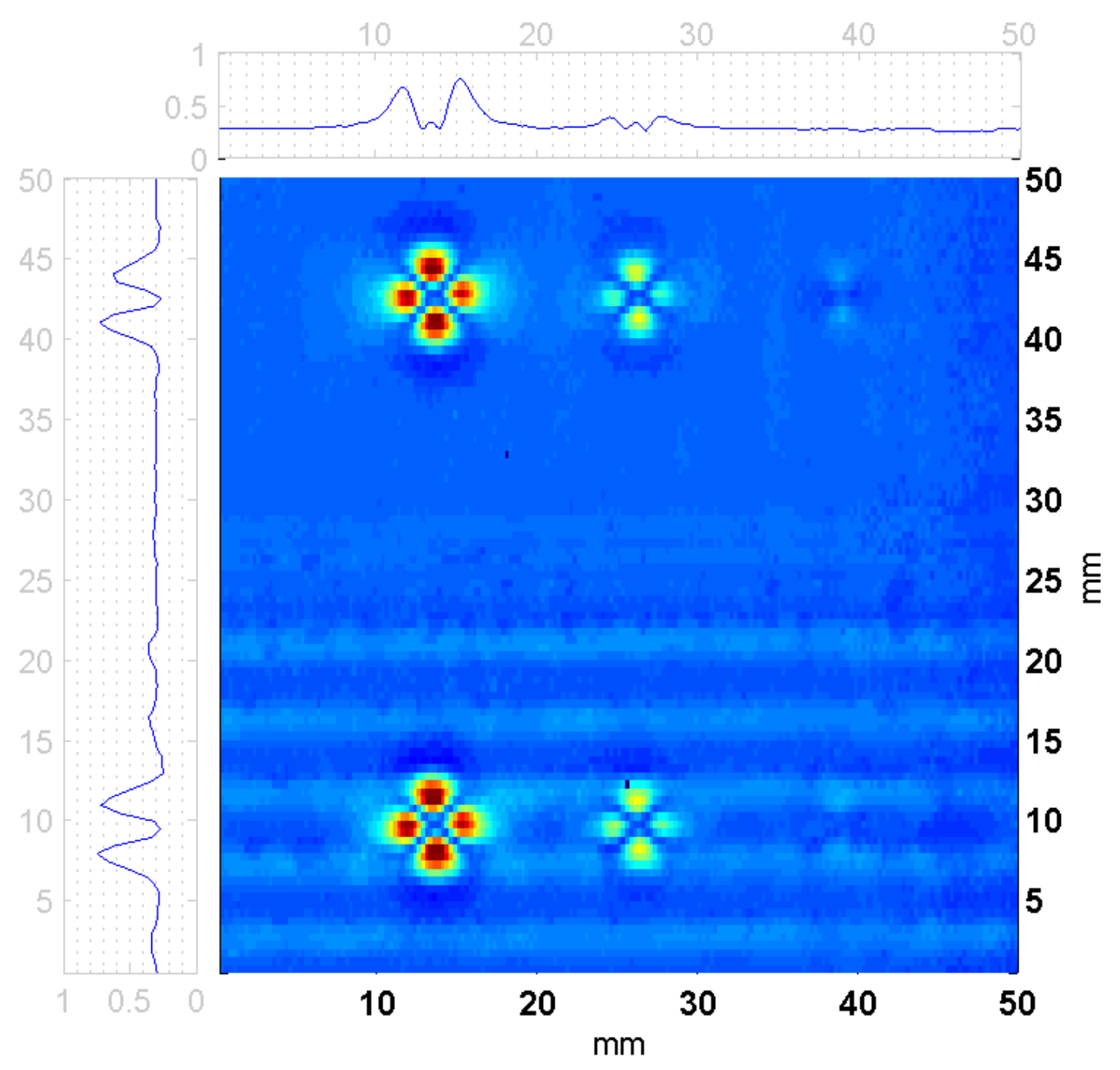

Figure B-6.

Sample:

PB Block

Mitigated Region: Lower half

Instrument:

ZETEC MIZ 22

Probe:

ZETEC 3479-1-A Plus Point (run in differential mode)

Scan Size:

$50 \mathrm{~mm} \times 50 \mathrm{~mm}$

X Step Size: $\quad 0.25 \mathrm{~mm}$

Y Step Size: $\quad 0.50 \mathrm{~mm}$

Test Frequency: $\quad 50 \mathrm{kHz}$

Gain:

$36 \mathrm{~dB}$

$\mathrm{V} / \mathrm{H}$ :

$8 / 8$

Phase:

294 degrees 


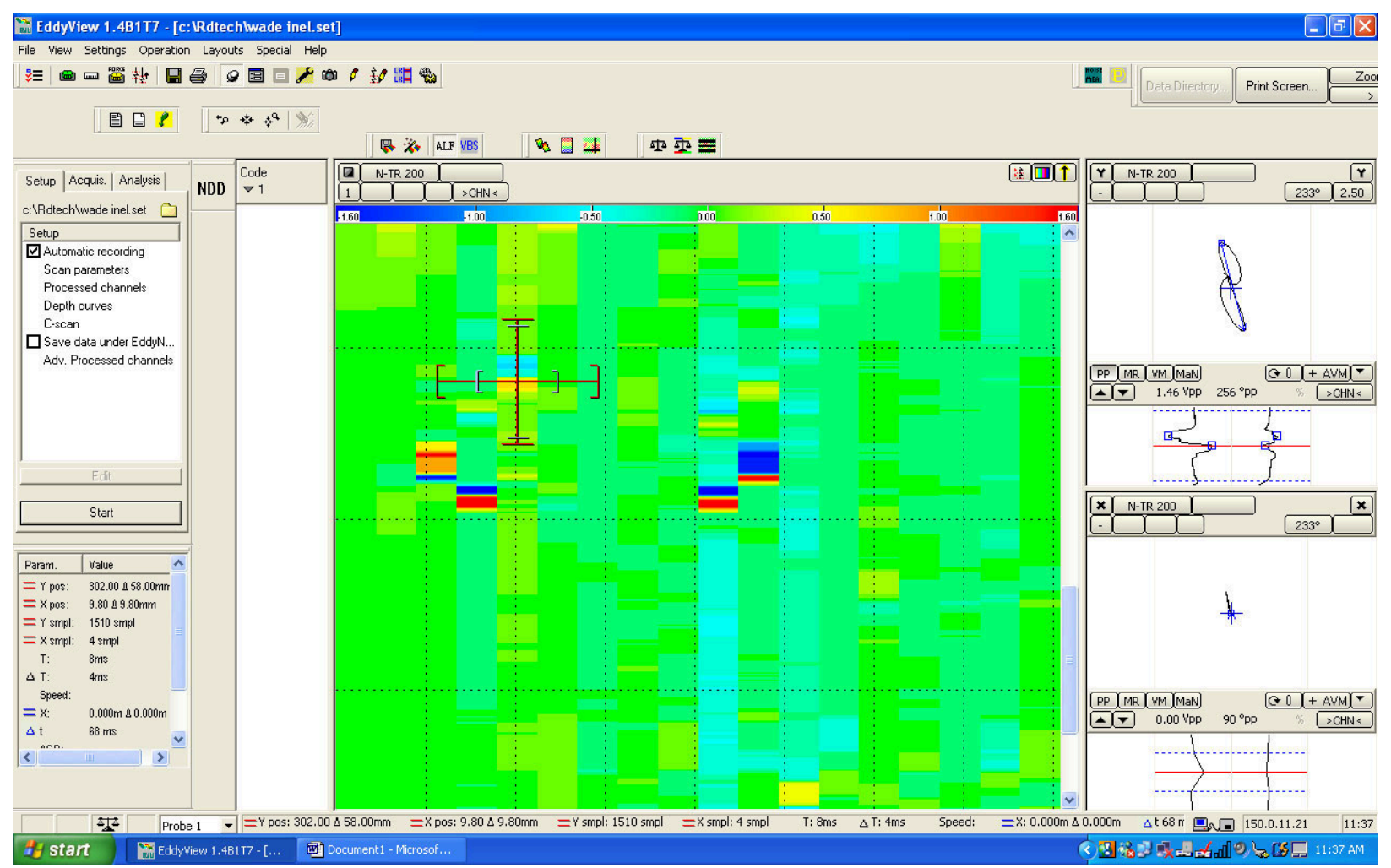

Figure B-7.

Sample:

PB Block

Mitigated Region: Left side

Instrument: $\quad$ RD Tech TC 7700

Probe: $\quad$ RD Tech Prototype CRDM Probe E342118A (TR mode)

Test Frequency: $200 \mathrm{kHz}$ 


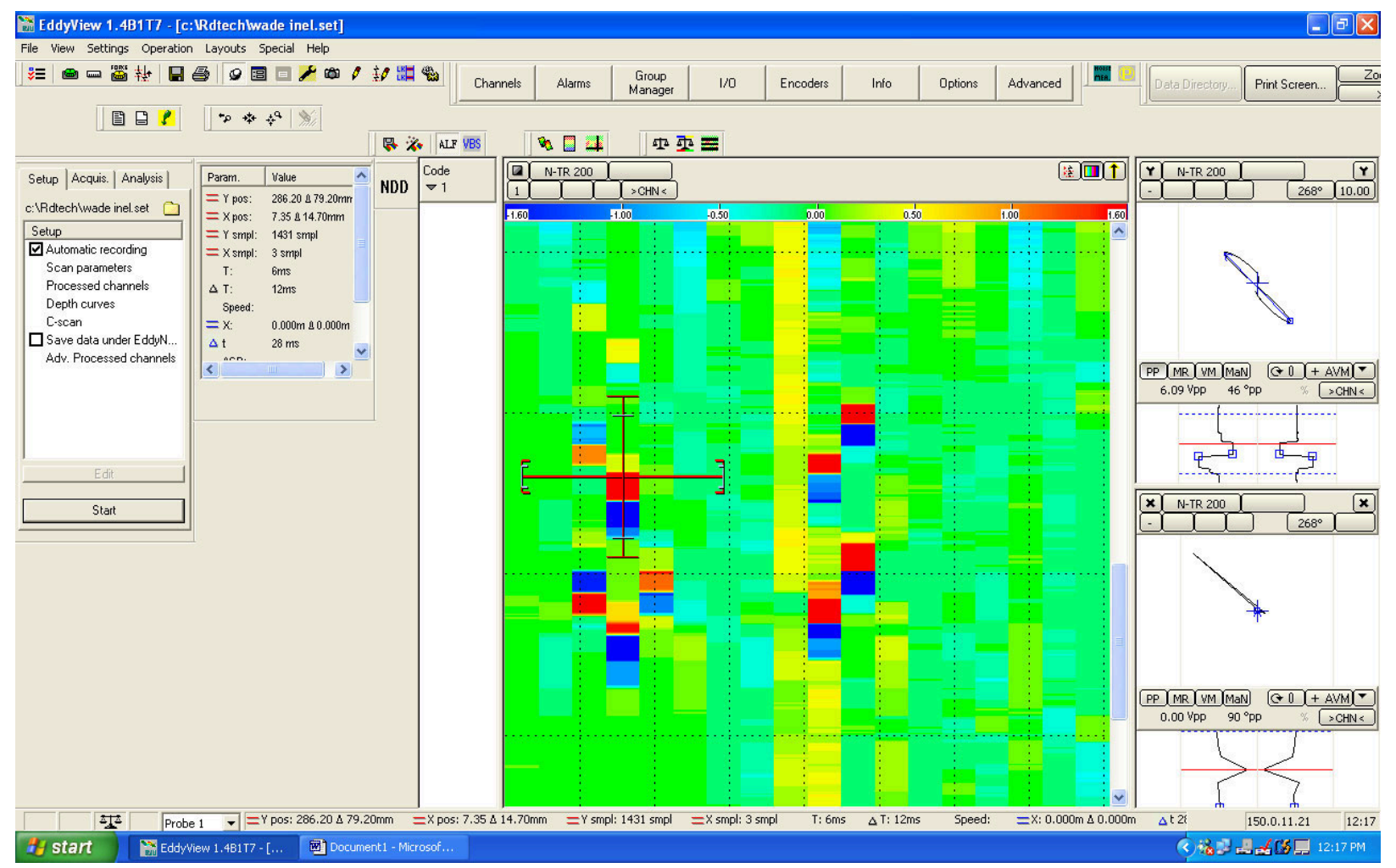

Figure B-8.

Sample: $\quad$ PB Block

Mitigated Region: Left side

Instrument: $\quad$ RD Tech TC 7700

Probe: $\quad$ RD Tech Prototype CRDM Probe E342118A (TR mode)

Test Frequency: $\quad 400 \mathrm{kHz}$ 


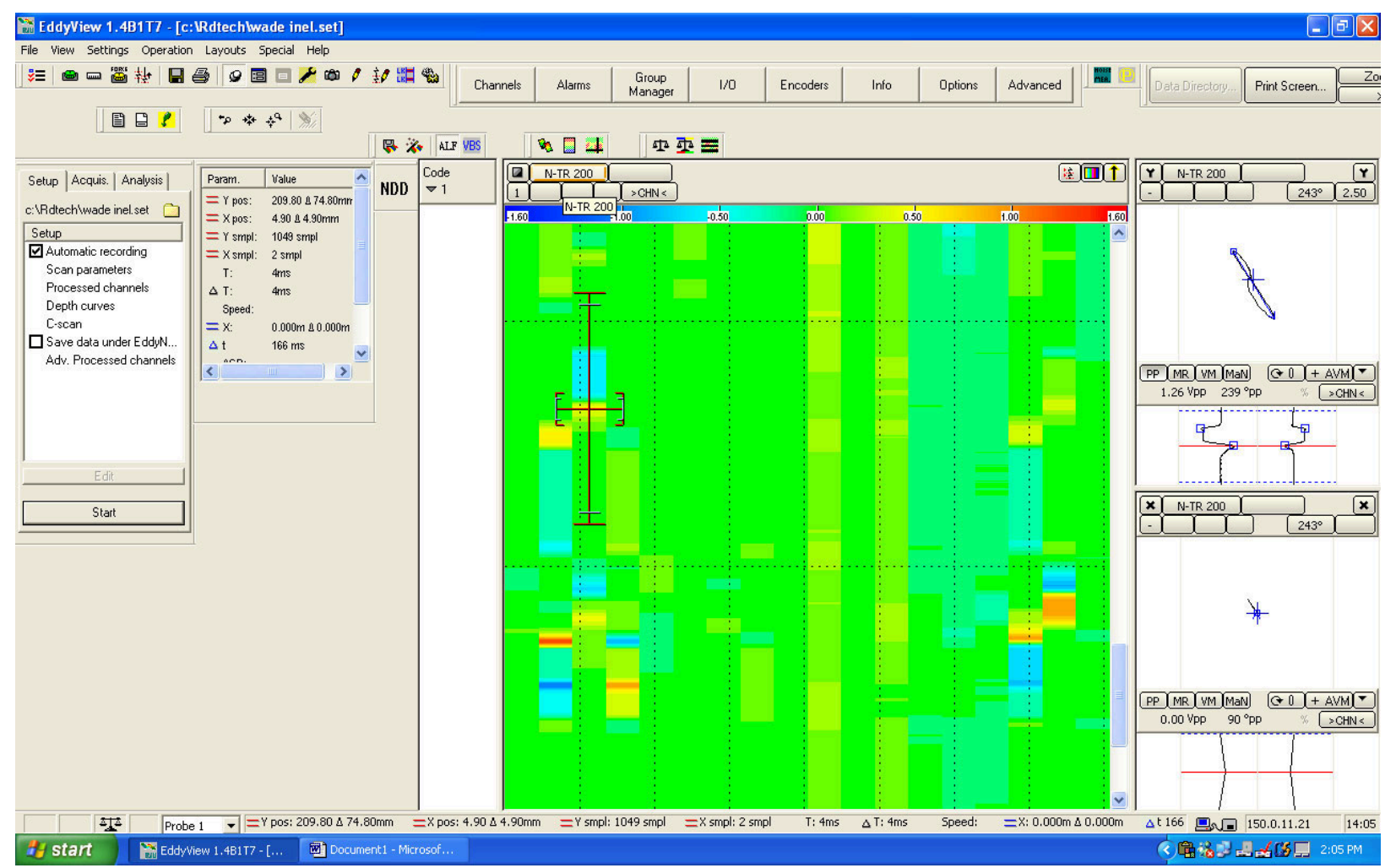

Figure B-9.

Sample: $\quad$ LP Block

Mitigated Region: Right side

Instrument: $\quad$ RD Tech TC 7700

Probe: $\quad$ RD Tech Prototype CRDM Probe E342118A (TR mode)

Test Frequency: $\quad 200 \mathrm{kHz}$ 


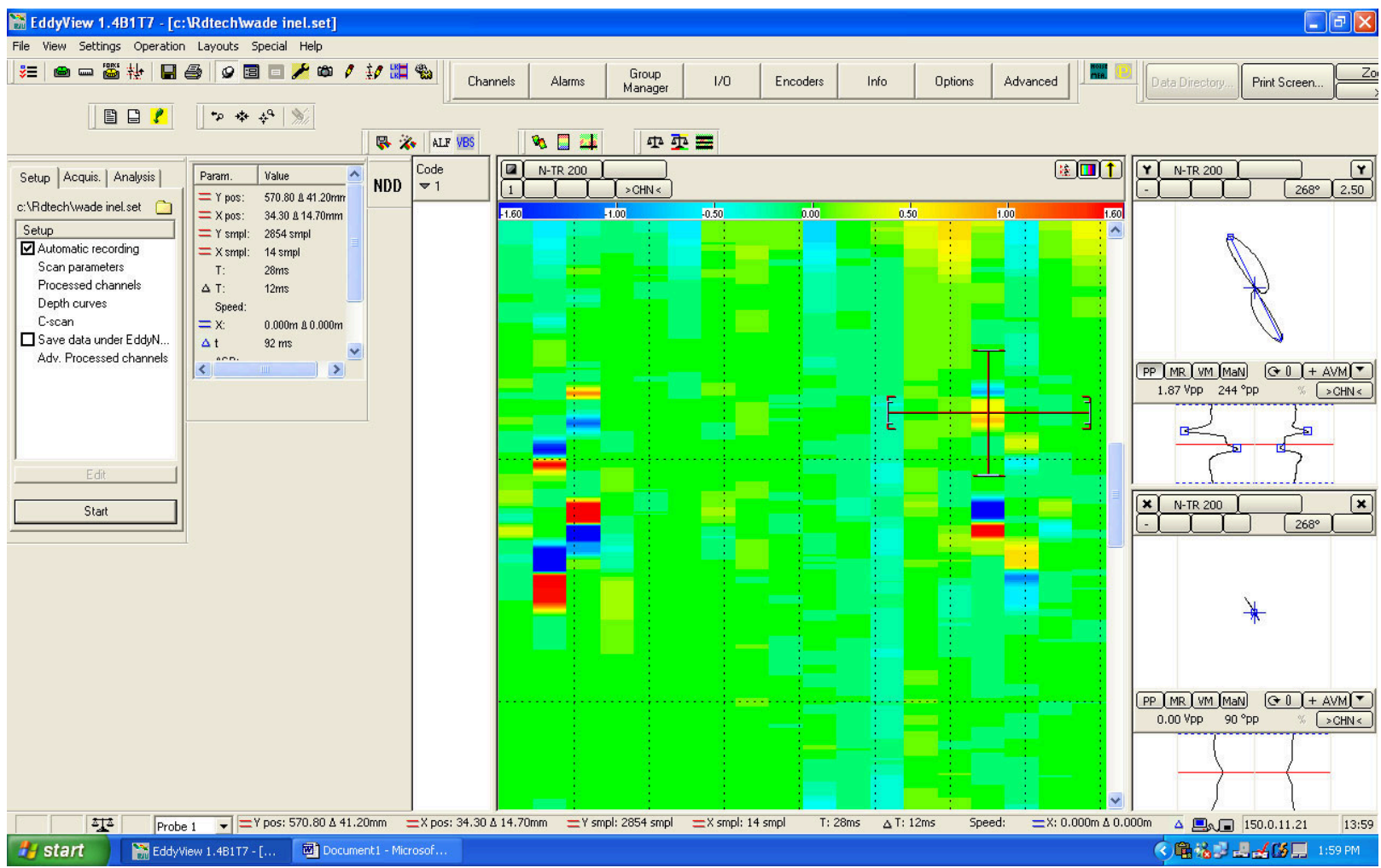

Figure B-10.

Sample: $\quad$ LP Block

Mitigated Region: Right side

Instrument: $\quad$ RD Tech TC 7700

Probe: $\quad$ RD Tech Prototype CRDM Probe E342118A (TR mode)

Test Frequency: $\quad 400 \mathrm{kHz}$ 


\section{Appendix C \\ Example of the Problem Caused by a Reflective Surface for the Visual Sensor}




\section{Example of the Problem Caused by a Reflective Surface for the Visual Sensor}

Applying a laser-stripe-based sensor to a shiny surface can cause misinterpretation of the profile. Although not an issue with a finish weld joint without an angle approaching 90 degrees, this appendix provides background on the reflective surface observation in the discussion section of this report. Figure $\mathrm{C}-1$ shows the setup of the visual sensor on a fillet weld. Figure $\mathrm{C}-2$ shows the result of the laser stripe on the two surfaces. Because the opposing surfaces reflect the light between each other, a butterfly effect is shown in the highly reflective surface. The larger the included angle in such a setup, the less of an effect is present. For the outer lid, the angle essentially becomes 180 degrees and produces none of this effect.

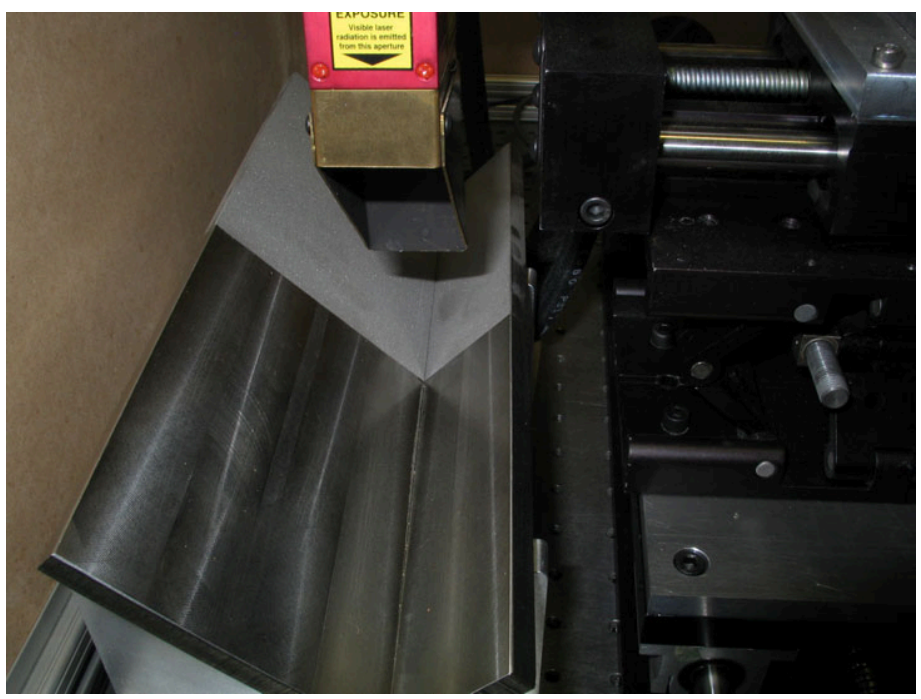

Figure C-1. Setup of a fillet weld to demonstrate the difference between a shiny and dull surface.

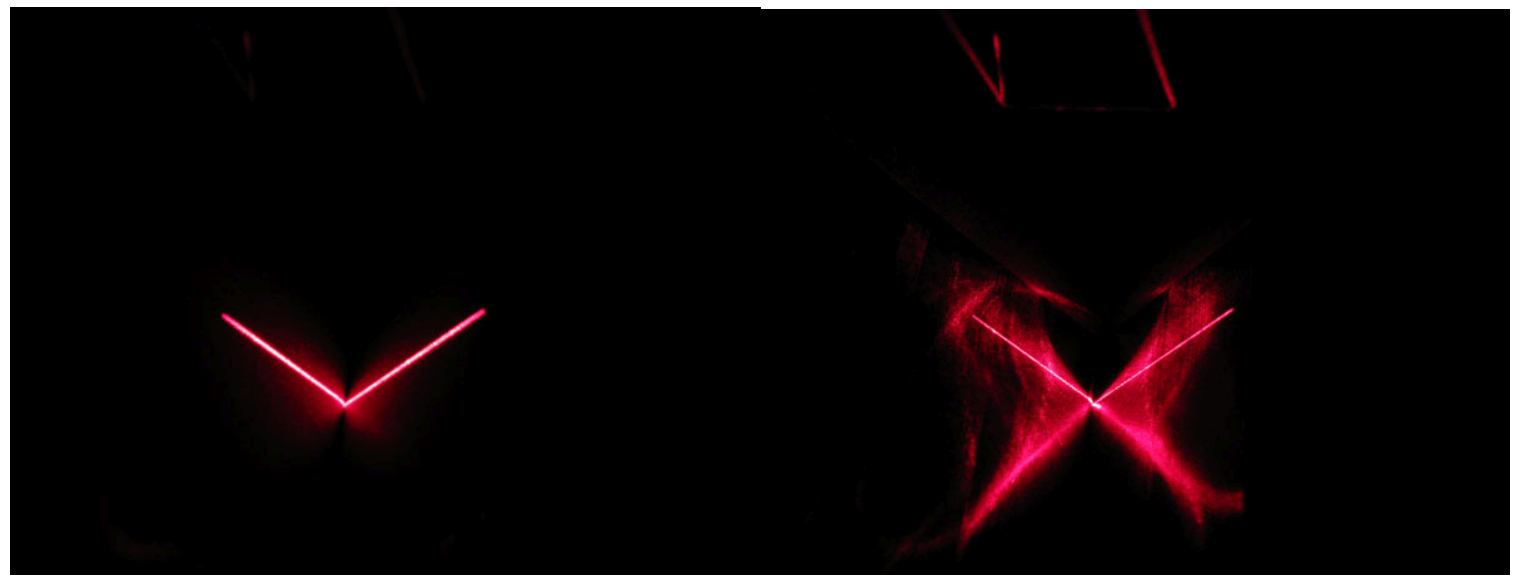

(a) Result from dull surface.

(b) Result from shiny surface.

Figure C-2. Resulting laser stripe comparing a dull surface to a shiny surface. 
